Issued by Sandia National Laboratories, operated for the United States Department of Energy by Sandia Corporation.

NO'TICE: This report was prepared as an account of work sponsored by an agency of the United States Government. Neither the United States Government nor any agency thereof, nor any of their employees, nor any of their contractors, subcontractors, or their employees, makes any warranty, express or implied, or assumes any legal liability or responsibility for the accuracy, completeness, or usefulness of any information, apparatus, product, or process disclosed, or represents that its use would not infringe privately owned rights. Reference herein to any specific commercial product, process, or service by trade name, trademark, manufacturer, or otherwise, does not necessarily constitute or imply its endorsement, recommendation, or favoring by the United States Government, any agency thereof or any of their contractors or subcontractors. The views and opinions expressed herein do not necessarily state or reflect those of the United States Government, any agency thereof or any of their contractors.

Printed in the United States of America. This report has been reproduced directly from the best available copy.

Available to DOF and DOE contractors from

Office of Scientific and Techrical Information

PO Box 62

Oak Ridge, TN 37831

Prices available from (615) 576-8401, FTS 626-8401

Available to the rublic from

National Technical Information Service

US Department of Commerce

5285 Port Royal Rd

Springfield, VA 22161

NTIS price codes

Printed copy: A04

Microfiche copy: A01 
SAND89-0629

\title{
A CENTRAL REFRIGERATION SYSTEM TO BUPPORT MULTIPLE ENVIRONMENTAL TEST CHAMBERS: DESIGN, DEVELOPMENT, AND EVALUATION
}

\author{
R. G. Baca \\ Fluid Mechanics and Heat Transfer Division III \\ K. M. Miller \\ Digital Systems Division \\ K. I. Shipley (retired) \\ Experimental Mechanics Division \\ Sandia National Laboratories \\ Albuquerque, NM 87185
}

\begin{abstract}
A pilot plant project was undertaken to develop a central refrigeration compressor station capable of providing the necessary cooling to a network of nine independently-controlled environmental test chambers operating at temperatures of $-85^{\circ} \mathrm{F}$ to $350^{\circ} \mathrm{F}$. Design features of the central two-stage (cascade) vapor compression refrigeration system are described. Computer control of the central refrigeration station is a major contribution to the improved efficiency of the overall system. A second computer-control system was developed to perform the task of environmental chamber control, test management, and chamber performance monitoring. Data on performance of the Climatic Central Refrigeration system (CCRS) are presented.
\end{abstract}


The following is a list of personnel who are major contributors to the writing and preparation of this report:

- R. G. Baca

Control, Performance, and Evaluation

- K. M. Milier

- K. L. Shipley Computer control systems

- L. A. Wilson Refrigeration system Drawings and Temperature control

\section{ACKNOWLEDGMENTS}

The following personnel are acknowledged for their contribution to the success of the pilot plant development:

- G. R. Noel

- R. D. Pope

Electrical Design and Installation

- L. A. Wilson Mechanical Design and Installation control Hardware and software

Also acknowledged is the assistance of $R$. $I$. Shuman in the early planning of the project, the advice of F. J. Potts in functional planning of the facility, and D. R. Helmich for reviewing this report. 
1.0 BACKGROUND............................ 1

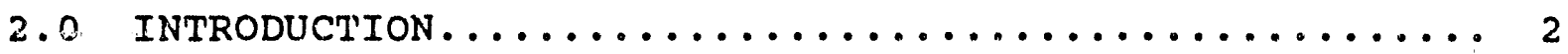

3.0 CCRS FACILITY......................... 4

3.1 Basic Cascade Design.......................6. 6

3.2 Design Considerations..................... 7

3.3 Central Refrigeration system................. 9

3.4 Temperature Test Chambers.................... 14

3.5 Electrical Installation...................... 18

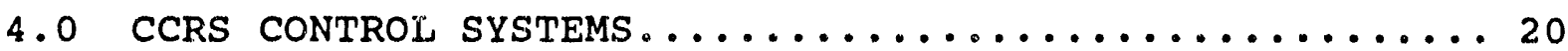

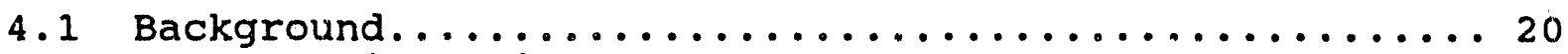

4.2 CCRS Refrigeration Control.................. 23

4.2.1 Compressor Capacity Control..............23

4.2.2 Cascade Heat Exchanger Control.............26

4.3 Environmental Chamber Control................. 27

5.0 EVALUATION PROCEDURE....................... 31

6.0 CCRS PERFORMANCE AND EVALUATION.............. 33

6.1 Control system Performance................... 33

6.2 Chamber Performance............................ 38

6.3 System Efficiency....................... 40

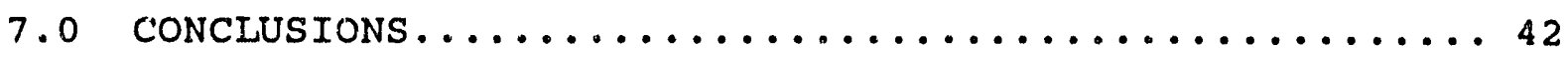

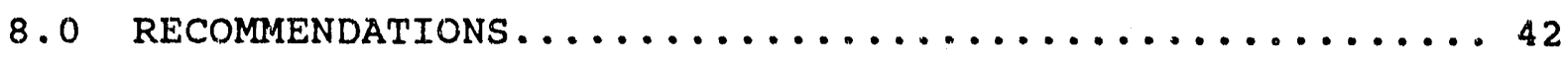

9.0 REFERENCES............................ 43

APPENDIXES

APPENDIX A - Compressor station Schematic...........44 


\section{FIGURES}

Page

3.1 CCRS Pictorial........................ 5

3.2 Basic Cascade System with Compressor False Loading.... 8

3.3 Essential Components of CCRS Refrigeration System.... 12

3.4 Pictorial of Central Compressor station........... 13

3.5 CCRS Refrigeration and Control schematic.......... 16

3.6 Rear View of Chamber Illustrating Economizer

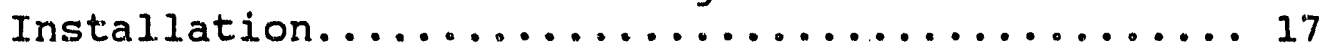

3.7 Electrical Schematic of CCRS and Chambers.......... 19

4.1 CCRS Control Component Diagram................ 21

4.2 CCRS Control Component Diagram................ 24

4.3 Simple Feedback Control system................. 28

5.1 RAMP4 Temperature Profile.................. 32

6.1 R-13 Suction Pressure and Compressor output Response.. 33

6.2 R-13 Discharge Pressure and Cascade Output Response... 34

6.3 R-502 Suction Pressure and Compressor Output Response. 36

6.4 EC-196 Temperature and R-13 Compressor Output

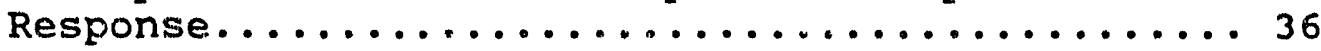

6.5 Conventional (Stand-Alone Chamber) R-13 suction and Discharge Pressure Response................. 37

6.6 CCRS R-13 Suction and Discharge Pressure Response.... 37

6.7 Chamber Temperature Response to RAMP4 Profile....... 38

6.8 R-13 Compressor Output for staggered and Maximum Pull-Down Rates Using the RAMP4 Profile........40

A-1 Complete Refrigeration Schematic of CCRS..........46 


\section{A CENTRAL REFRIGERATION SYSTEM TO BUPPORT MULTIPLE ENVIRCNMENTAI TEST CHAMBERS: DESIGN, DEVELOPMENT, AND EVALUATION}

\subsection{BACKGROUND}

The Climatic Facility at Sandia National Laboratory (SNL) uses 53 environmental test chambers to simulate a variety of climatic conditions. Most of these have the capability to operate between temperatures of $-85^{\circ} \mathrm{F}$ to $350^{\circ} \mathrm{F}$, with programmed changes during a test. To provide the low temperatures, a twostage vapor compression refrigeration system (i.e., a cascade system) is normally used. In standard commercial practice, each temperature chamber has its own refrigeration system to allow a stand-alone unit.

In recent years, a number of test chambers at the climatic Facility have exceeded their useful life in test capabilities and/or maintainability. As a replacement for this outdated equipment, consideration was given to acquiring a multiple chamber system with a single refrigeration compressor station capable of providing the necessary cooling for all chambers. A further requirement is that the temperature control of each chamber would operate independently from all other chambers. The necessity for rapid chamber cooling would require the continued availabilicy of liquid refrigerant at the expansion valve of each chamber.

A query of environmental chamber manufacturers revealed that no multiple chamber equipment was available that would meet these requirements. Consequently, the development of such a system was undertaken. This report is a compendium of the essential ideas, design, and materials that went into the development of the climatic Central Refrigeration system (CCRS). Also included is an evaluation of system performance and recommendations for future development. 


\subsection{INTRODUCTION}

In the operation of temperature chambers, the refrigeration required to maintain a desired temperature level is normally a small fraction of the refrigeration required to lower the temperature in the chamber. This is especially true if the refrigeration system has been sized to provide a rapid temperature change (or pull-down), which is often required in environmental testing. Since most of the testing time is spent in maintaining a steady-state temperature in a chamber, the refrigeration system is typically operating well under its design capacity. In fact, most stand-alone temperature chambers have sufficient refrigeration capacity to provide cooling to a multiple number of chambers. It is this extra capacity that was the basis for a proposal to develop a network of several chambers with refrigeration provided by a central compressor station (i.e., a multiple-chambered system with a single refrigeration unit).

There are other attributes that have prompted enthusiasm for this project. The principle merits that can be realized for such a system are briefly presented below:

- Efficiency - the combined cooling load for the multiple chambers should result in a better match of refrigeration capacity to chamber requirements. Efficiency is further enhanced with the practicality of compressor speed control for a central refrigeration system. These assets would essentially eliminate the need for false loading of the compressor, which is normally required to maintain a positive suction pressure, and adequate compressor cooling at near-zero refrigeration loads.

- Mintenance - the accessibility and maintenance of a centralized refrigeration system will be more effective than for the many separate systems if stand-alone units were used. Similar reasoning can be made for a centralized computer-control system that would enhance the operation control and test data management for the multiple chambers.

- Chamber stacking - a savings in floor space can be realized if test chambers can be stacked. The absence of refrigeration systems for each chamber allows smaller chambers to be stacked. Additional space savings is possible due to the closer grouping of chambers on the floor. 
- Reliability - To improve the dependability of a single refrigeration system, a redundant pair of compressors can provide a continuity of normal service in the event of a compressor malfunction. In addition, the redundancy will provide extra capacity when a test chamber requires an additional cooling capability (i.e., achieving a $8^{\circ} \mathrm{F} / \mathrm{min}$. pull-down).

- Cost - A single high-performance refrigeration system will cost less, give greater reliability, and operate more economically than multiple stand-alone systems designed to provide standard performance.

- Noise Abatement - A central refrigeration system allows for all the compressors to be placed in a sounddeadening enclosure to reduce compressor noise in the work environment.

Development of the central refrigeration concept does present an element of risk that the system may not operate as envisioned. A variety of design problems need to be addressed and properly resolved. Some of the more important areas of concern include the following:

- Temperature control - Can acceptable chamber tolerance be maintained while using parallel evaporator coils common to a single supply line?

- Liquid Refrigerant supply - Chambers that are placed at a great distance from the central refrigerator station, or chambers that are idle for long periods of time, may not always have liquid refrigerant available at the control solenoid.

- Qil Return - Layout of the entire system must allow for the retrieval of coinpressor oil from the chamber evaporators and its re-introduction into the compressor system.

- Refrigerant capacity control - Can the capacity control of the compressors be managed with sufficient proficiency to 1) decrease compressor power consumption during periods of minimum cooling demand and, 2) provide adequate suction pressure to allow sufficient refrigerant expansion at very low temperature demands?

The remainder of this report discusses the implementation and evaluation of the CCRS which address the design goals and concerns. 


\subsection{CCRS FACILITY}

The CCRS was conceived as a network of nine temperature chambers with individual temperature controls and heating elements at each chamber, but with a single refrigeration station to provide, on demand, the required liquid refrigerant to all of the chambers. The feasibility of a central cascade refrigeration system has been studied and was concluded to be a viable alternative to existing single chamber units. A preliminary design and layout of the system evolved and approval for its development was given in late 1985. Procurement of component: began in April 1986, assembly of the CCRS started in October 1986, and the first trial run of the refrigeration system was conducted in september 1987. The scope ,f this project is best illustrated by the pictorial presented as Figure 3.1 .

Referring to the pictorial of Figure 3.1, and starting at the extreme left, the following major features of the CCRS can be identified:

1. instrument racks with two personal computers (PCs for chamber temperature control/test management and refrigeration control)

2. the central compressor station, water-cooled condenser, and associated refrigeration circuits

3. cabinet containing the cascade heat exchanger and, at the bottom, the receiver for the low temperature liquid refrigerant

4. two motor speed drives (on the wall near the corner)

5. four small ( $8 \mathrm{ft.}{ }^{3}$ ) temperature chambers (with controller rack between stacks)

6. four medium-size $\left(27 \mathrm{ft.}{ }^{3}\right)$ temperature chambers (and controller rack)

7. one large (64 It.3) temperature chamber (with controller rack at the extreme right)

The principle distinction of this multiple chamber system, from that of a conventional (stand-alone) temperature chamber, is the central refrigeration system. Accordingly, the design of the central refrigerator will be the first topic in the description of the CCRS development. 


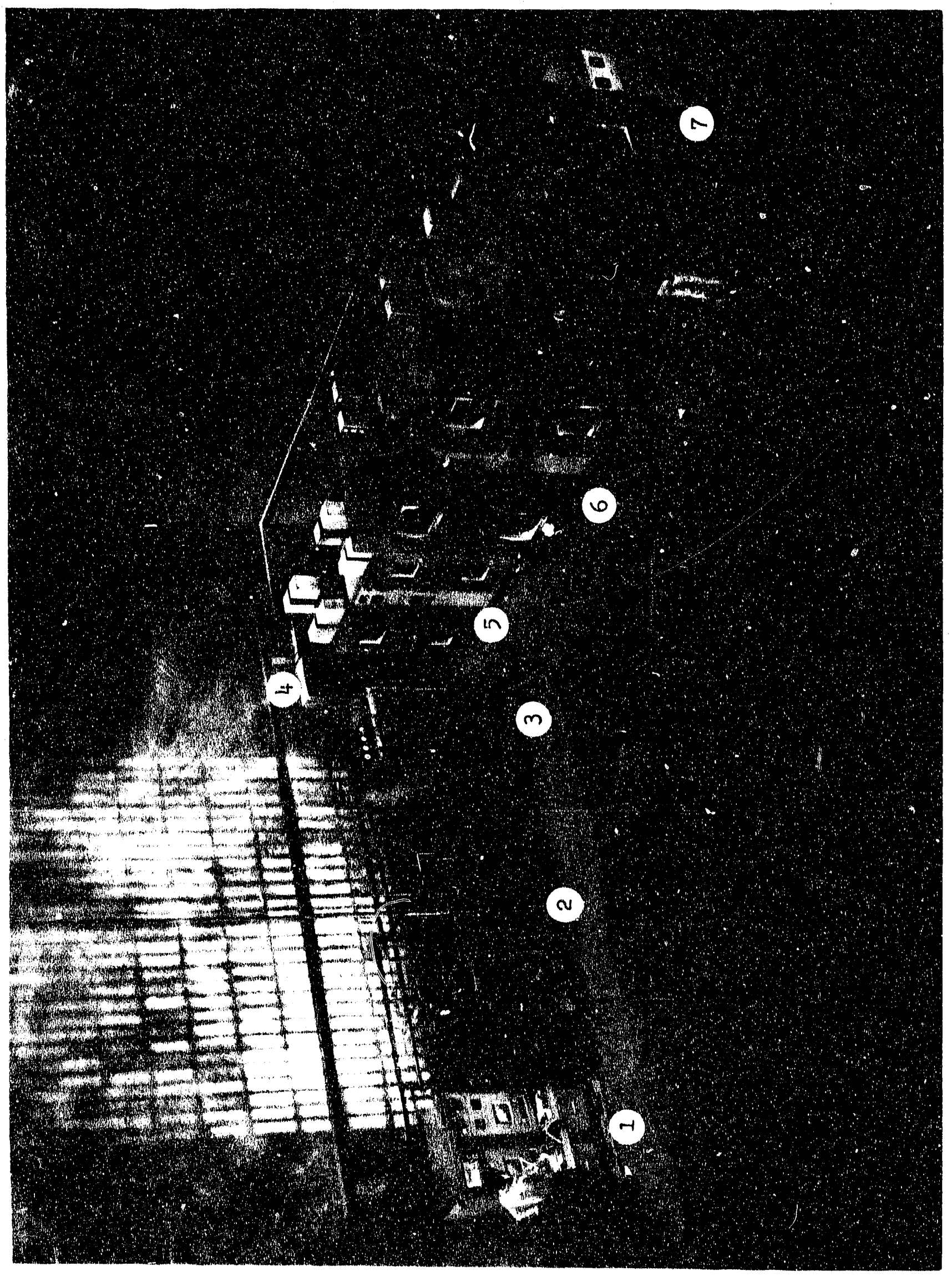




\subsection{Basic Cascade Design}

The basic cascade refrigeration system [1] is shown schematically in Figure 3.2. There are two refrigeration circuits (low temperature stage and high temperature stage), each with a compressor, condenser, evaporator, and a false loading circuit. In normal operation, the low temperature stage removes heat from the chamber (on the right in Figure $3.2)$ by the expansion of high pressure liquid refrigerant into the low pressure chamber evaporator. The refrigerant vapor passes to the low stage compressor, which has a two-fold function: 1) withdraw refrigerant vapor from the evaporator at a rate sufficient to maintain the required low expansion pressure, hereafter called the suction pressure; and, 2) compress the refrigerant to a superheated state sufficient to permit heat transfer to the high temperature stage at the cascade condenser. In the high temperature stage, a similar process moves the heat from the cascade evaporator to the water-cooled condenser; here heat is removed frorm the system in the cooling water (nominally at $70^{\circ} \mathrm{F}$ ). In standard practice the two compressors are identical, but operate with different refrigerants. The two refrigerants are selected to allow the compressors to operate at nearly the same discharge pressure (nominally 200 psia), while generating different temperatures when the refrigerant expands in its respective stage evaporator. In this report, the refrigerants that will l be discussed are R-13 for the low temperature stage and R-502 for the high temperature stage. For a compressor operating at a discharge pressure of 200 psia and a suction pressure of 20 psia, the corresponding condensing, and boiling temperatures are $8^{\circ} \mathrm{F}$ and $-104^{\circ} \mathrm{F}$ for $\mathrm{R}-13$, and $90^{\circ} \mathrm{F}$ and $-38^{\circ} \mathrm{F}$ for $\mathrm{R}-502$. The design temperature of the cascade condenser is $-20^{\circ} \mathrm{F}$ to ensure the $R-13$ refrigerant is liquefied.

To control the temperature in the test chamber, a solenoid valve is placed in the liquid $\mathrm{R}-13$ line just ahead of the expansion valve (see Figure 3.2). This solenoid is operated by a temperature controller which senses the air temperature within the test chamber. When the chamber temperature is at, or less than, the desired temperature setpoint, the solenoid is closed to stop the flow of refrigerant into the cooling coils. Consequences of this action are to 1 ) reduce the cooling to the compressor by stopping the flow of low temperature vapor refrigerant that removes the heat gene:ated by the compressor, and 2) generate negative pressures (vacuum; downstream of the closed solenoid. To avoid these two situations, a hot gas bypass (located before the condenser) and a liquid bypass (after the condenser) are used to provide the "false" load to the compressor and, thereby, maintain a positive suction pressure and adequate compressor cooling. The refrigeration circuits required to accomplish these tasks are shown 
schematically in Figure 3.2 (for both stages) and labeled as False Loading. Some variation of this false loading is found in most refrigeration systems. AlI methods of compressor false loading require compressor work that is not used to cool the chamber and result in lower system efficiencies.

The schematic of Figure 3.2 illustrates only the basic components and circuits common to all cascade refrigeration systems. For reasons of clarity such items as filters, driers, oil return circuits, receivers, etc., which are normally a part of all refrigeration systems, were not included in Figure 3.2 . Information on how this ancillary equipment is used in refrigeration circuits can be found in References 2 and 3.

\subsection{Design Considerations}

A principle design goal of the CCRS was to reduce or eliminate the false loading of compressors thereby increasing system efficiency. If the refrigeration system capacity (compressor output) can be controlled to equal the chamber demand (refrigeration load), the suction pressure would remain essentially constant and false loading could be eliminated. This task can be accomplished by a combination of techniques consisting of:

a) Networking a number of chambers to operate from a single refrigeration system so that a greater percentage of available compressor capacity will be utilized.

b) Selecting compressors with multiple cylinders and a capability to allow cylinder unloading.

c) Operating two or more compressors in parallel for each stage to provide flexibility (and reliability) of refrigerant supply.

d) Using variable speed motors to further control compressor output capacity.

An important consideration is that of reliability; the cooling of multiple test chambers from a single refrigeration system has the unfavorable prospect of multiple test failures in the advent of refrigeration system failure. This problem can be mitigated (but not eliminated) by careful design and the inclusion of redundancy for major components of the refrigeration system. It has already been suggested in technique a), above, that a dual set of compressors could facilitate capacity control and provide a degree of reliability in the event of a single compressor failure; operation of the two units would be switched periodically to facilitate equal 


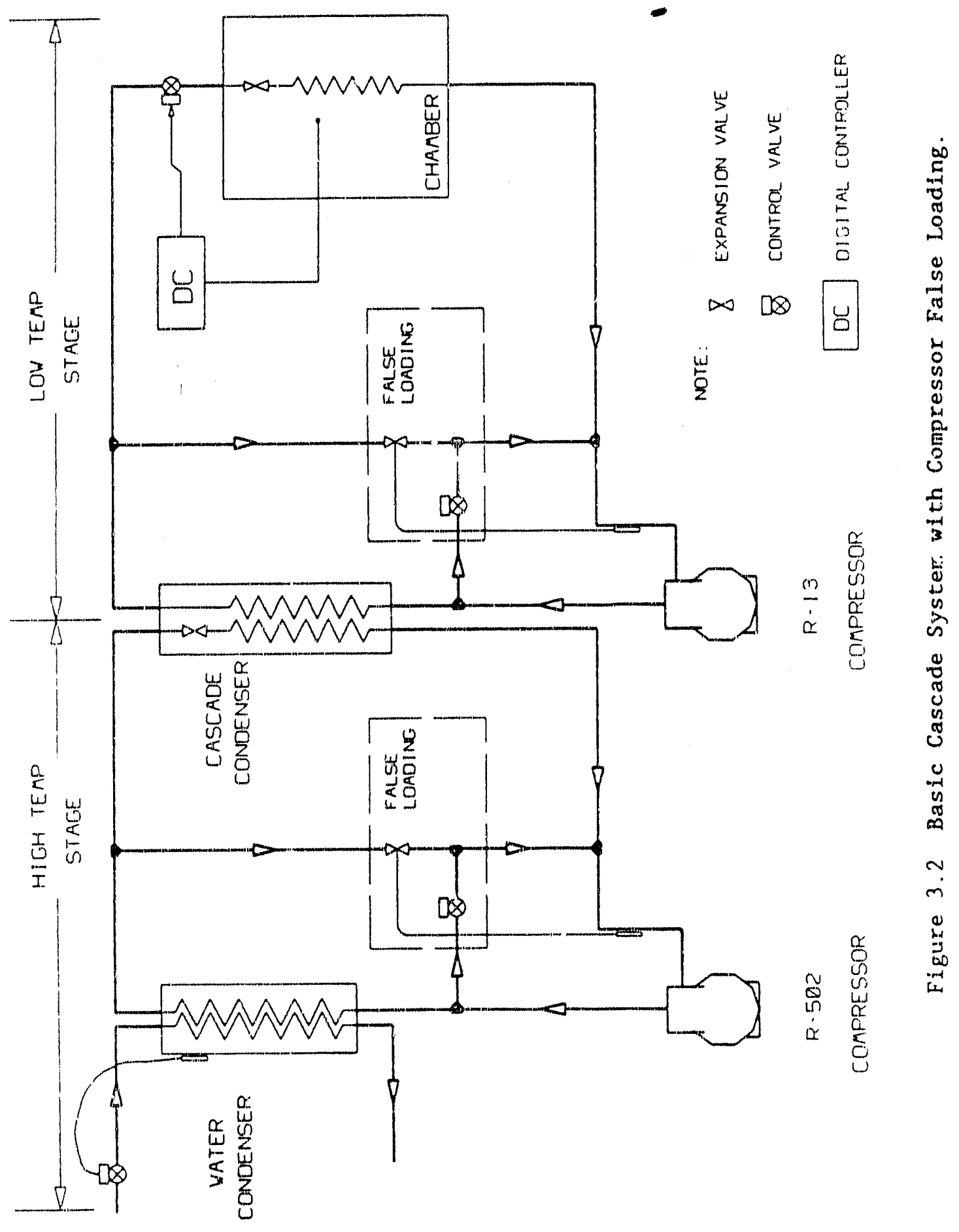


wear. This concept can be extended to some of the other critical parts of the overall system.

The concept of multsple test chambers being supplied from a single refrigerant line requires a guarantee that liquid refrigerant, at about $-10^{\circ} \mathrm{F}$, will be continuously available at the chamser thermal expansion valve (TEV). The problem is made more difficult by the necessity of a long supply line (to reach the furthermost chamber) and the possibility of refrigerant. flow interruption for prolonged intervals (when there is no cooling demand). A solution requires keeping the supply line cold and purged of vapor. Both tasks can be accomplished by bleeding minute amounts of refrigerant through IEV's at intervals along the supply line. This process further reduces the need for false loading of the low temperature stage compressor.

\subsection{Central Rerrigeration Bystem}

An analysis to estimate the refrigeration capacity required to sustain a minimum temperature for all. nine temperature chambers (a total of $204 \mathrm{ft.}^{3}$ ) of the cCRS dictated a compressor capacity of approximately $75 \mathrm{cfm}$. Further considerations on how the nine chambers would be used (e.g., some pulling down, some at low temperature, and some in a heating phase) suggested that, on the average, a $60 \mathrm{cfm}$ capacity would be sufficient for each temperature stage. That is, the compressors are not being sized for maximum chamber cooling (pull-down). Accordingly. the basic compressor unit was selected to be a carrier 5F60, six-cylinder, with a capacity of $59.6 \mathrm{cfm}$ at a speed of 1750 rpm. There are four compressors divided into separate compressor pairs. This allows for a redundant compressor to be available in the event of a compressor malfunction or to provide additional capacity during peak chamber demand. Each compressor pair (designated as pair A or B) consists of a compressor connected to either the high or low temperature stage. All the compressors are belt-driven by identical $25 \mathrm{HP}$ motors. (Belt-driven compressors allow notor replacement without risk of refrigerant loss.)

To achleve the goal of minimal false loading of compressors, it is necessary to control the output capacity of the compressors. This is accomplished by means of 1) compressor cylinder unloading and, 2) variable compressor speed. A summary of these procedures follows.

'The compressors were modified, per manufacturer's specifications, to aliow up to four of the six cylinders to be unloaded on command of an external capacity controller. The unloading of cylinders is accomplished by activating a solenoid that applies compressor oil pressure to force the cylinder 
intake valve to remain open. (An external oil cooler is used on each ccmpressor to ensure acceptable oil temperature and pressure during operation.) This unloading capability permits each compressor output to be controlled over the nominal range of 20 to $60 \mathrm{cfm}$, in increments of $10 \mathrm{cfm}$.

Both motor compressors for the low temperature stage $(R-13$ circuit) are variable speed units. They are equipped with variable frequency $A C$ drives to allow the compressors to operate between speeds of 400 RPM and 1750 RPM. For these two compressors, the combined capability of cylinder unloading and variable speed permits a continuously variable-controlled refrigerant output from approximately 4.5 to $60 \mathrm{cfm}$ for each of the R-13 compressors. Compressors for the high temperature stage (R-502) operate at the constant speed of 1750 RPM.

Considering the availability of both compressors, the total range of compressor capacity for the high temperature (R-502) stage is from 20 to $120 \mathrm{cfm}$, in steps of $10 \mathrm{cfm}$. Similarly, speed control for the two low temperature stage compressors permit a continually varying output that ranges from 4.5 to 120 cfm.

Heat removal from the CCRS is accomplished by rejection to cooling water which is supplied at a nominal temperature of $75^{\circ} \mathrm{F}$. Approximately $93 \%$ of the total heat rejection is at the R-502 condenser; a Carrj-r 09RH027 water-cooled unit. Water circulation through this condenser is controlled by pressure regulating valves adjusted to maintain an $R-502$ compressor discharge pressure of 185 psig. A small amount of heat (approximately $6 \%$ of the total) is removed by a water-cooled desuperheater located in the R-13 compressor discharge line just prior to the cascade condenser; the regulating water valve opens when $\mathrm{R}-13$ temperature is greater than $100^{\circ} \mathrm{F}$ at the exit of the desuperheater. Finally, a minimal amount of heat (approximately 1\%) is extracted from the system at the compressor oil coolers.

A cascade heat exchanger is used to transfer heat from the low stage system (i.e., R-13 condensing) to the high stage (R-502 evaporating). The cascade used in the CCRS was fabricated by Russells Technical Products, Inc., of Holland, Michigan; the condenser consists of a stack of 28-coiled, tube-in-tube heat exchangers. The high stage $\mathrm{R}-502$ refrigerant is supplied through an array of six solenoid thermal expansion valves (arranged in parallel to permit control of the liquid R-502) to the 28 tube distributor on the evaporator side of the cascade. Refrigerant vapor from the $R-13$ compressors is first passed through a water-cooled desuperheater before entering the cascade condenser. Liquid R-13 passes from the cascade into a 
refrigerated receiver (Standard H8542 coil-in-shell condenser) and, frum there, to the test chamber evaporators.

A schematic of the basic components of the central compressor system are shown in Figure 3.3; an enlarged pictorial view of the compressor station is presentad as Figure 3.4. Nor shown in the schematic of Figure 3.3 are the oil separators, coolers, and return lines. In addition, false loading circuits, similar to those diagramed in Figure 3.2, were deleted from Figure 3.3 (they are pictured in Figure 3.4 for the $R-502$ stage only). An oil return dual-suction $r i s e r$ is indicated for the $R-13$ stage. This is to facilitate oil return from the chamber evaporators. A similar oil suction riser is in the $R-502$ vapor return line, but is deleted from Figure 3.3. (For information on the design and use of oil suction risers, see section 3.12 of Reference 2.)

Referring to Figure 3.4 , the numbered equipment illustrated in the pictorial are identified as follows:

1. instrument rack with control $\mathrm{PC}$ and four Honeywell DC-3000 controllers (two for motor speed control and two for cascade condenser control)

2. two high stage $(R-502)$ motor compressor units

3. two low stage $(R-13)$ motor compressor units

4. Oil separators (one in the $R-502$ discharge 1 ine and two in tandem in the $\mathrm{R}-13$ line)

5. water-cooled $\mathrm{R}-502$ condenser

6. false loading circuits for the high stage (there are two hot gas valves and two liquid expansion valves; one for each compressor)

7. water lines to the R-502 condenser (shown in white)

8. cascade condenser (there are six R-502 expansion valves in front of the coiled exchanger)

9. Iiquid $R-13$ accumulator

10. R-13 vapor receiver (for recovery of refrigerant during maintenance operations)

All refrigeration components, including the individual

chambers, and compressors can be isolated independently to minimize impact on the rest of the CCRS during maintenance and to reduce inadvertent refrigerant loss. Figure 3,4 also shows 


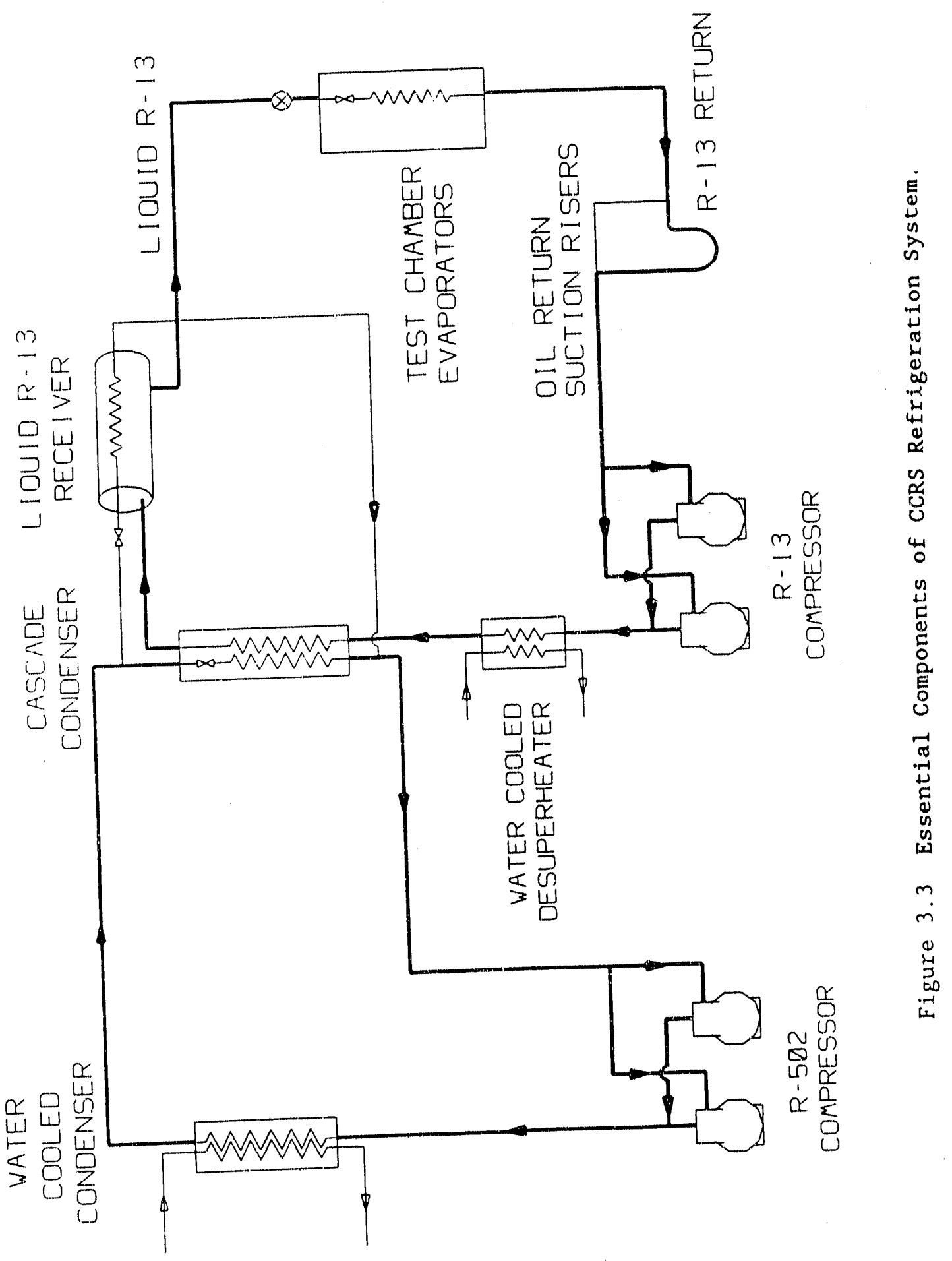


the compressor station in an open arrangement. In reality, this equipment is enclosed in a foam-lined cabinet for noise abatement, improved appearances, and added safety.

A more detailed drawing of the mechanical components that make up the central compressor station (Figure 3.4) is presented in Appendix A. Most of the components of the CCRS are found on conventional cascade refrigeration systems. The major distinction between the CCRS and the conventional refrigeration units is the control system and how it is used to satisfy the net temperature chamber demand. These added complexities are illustrated in Figure 3.5. A complete description of how the added features in Figure 3.5 are used is discussed in CCRS control systems.

\subsection{Temperature Test Chambers}

The variety of test item sizes and shapes that are submitted for environmental testing necessitates the availability of a range of chamber volumes for efficient use of floor space and energy expenditures. The CCRS has a selection of three chamber sizes: four small ( $\left.8 \mathrm{ft.}{ }^{3}\right)$ units, four medium $\left(27 \mathrm{ft.}{ }^{3}\right)$ units, and one large $\left(64 \mathrm{ft.}{ }^{3}\right)$ unit. The nine temperature test chambers were obtained from two sources; the four small chambers are refurbished units from Thermotron Corp., SM-8C Mini Max systems, and the five larger units were fabricated by Associated Environmental systems, Inc. To conserve floor space and minimize the length of the refrigerant supply lines, the smali and medium size chambers were stacked in pairs (refer to Figure 3.1). Refrigerant evapozators and electrical heaters for all nine chambers are sized to allow a nominal temperature ramp rate (either increasing or decreasing) of $6^{\circ} \mathrm{F} / \mathrm{min}$., or better. Temperature limits for the chambers are $350^{\circ} \mathrm{F}$ to $-85^{\circ} \mathrm{F}$.

Mention has been made of the need to guarantee availability of liquid $R-13$ refrigerant at each evaporator expansion valve. When the cooling requirement for a chamber has been idle for prolonged periods of time, the liquid refrigerant in the supply Iine can warm to temperatures above the boiling point (about $0^{\circ} \mathrm{F}$ ). To avoid this problem, each of the nine chambers has a small coil-in-shell heat exchanger (Economizer by superior Mfg.) inserted in the liquid line. This installation is shown in the photograph of Figure 3.6 ; it is also illustrated in the schematic of Figure 3.5. Referring to the numbered items in Figure 3.6 , they are:

1. Iiquid R-13 supply line

2. suction line returning $R-13$ vapor to the compressors 


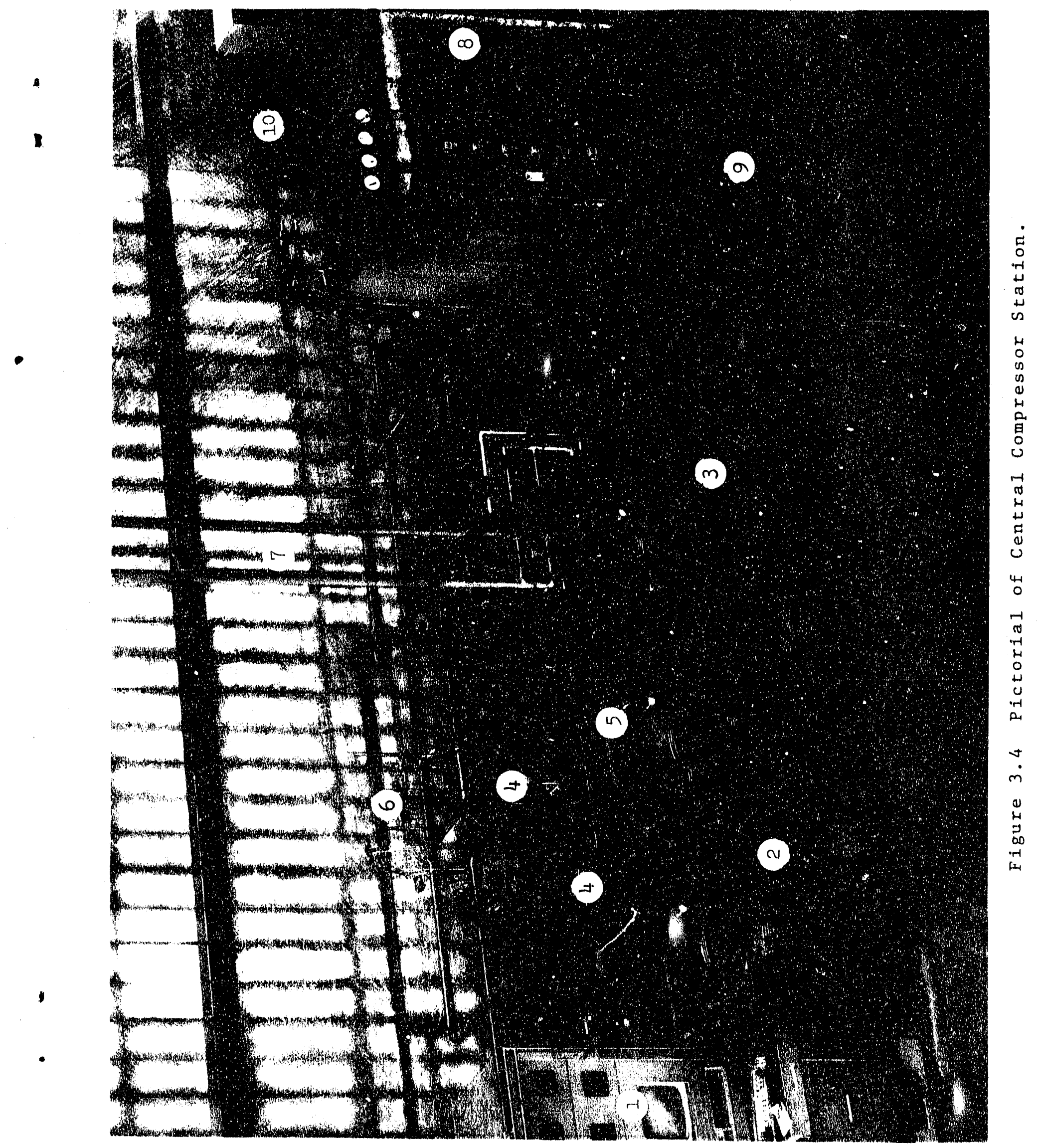


3. economizer (coil-in-shell exchanger) in the liquid supply line

4. small thermal expansion valve for the Economizer (note the TEV bulb on the Economizer suction line)

5. control solenoid valve

6. large thermal expansion valve for the chamber evaporator (again, note the TEV bulb on the evaporator suction line)

The placement of these economizers at each chamber insures the availability of liquid R-13 at the chamber TEV in two ways: the bleeding of a small quantity of refrigerant through the Economizer will purge the supply line of any vapor that has formed; and, 2) the small exchanger will cool the supply line well below the refrigerant saturation temperature. An added benefit of the bleeding through all the Economizers is greater mitigation of the false loading demands of the low stage compressors.

To satisfy the high temperature requirement, the chambers are equipped with electric heating elements. Control of power to the heaters is done using silicon-Controlled Rectifiers (SCRS), which are controlled by the chamber temperature controller. Additional information on the heaters, their SCR's, and air circulation fans is given in the Electrical Installation section.

Each chamber is equipped with a Honeywell UDC-5000 for the purpose of temperature control. These units have the capability of manual (i.e., stand-alone) operation, or they can communicate with a PC for downloading of test temperature profiles; this is covered in detail in section 4.3. The controllers are located in instrument cabinets adjacent to the chambers. Each chamber is also equipped with a digital hi-low temperature limit (supplied by cincinnati sub-Zero), which prevents over-ranging of prescribed test temperatures.

To integrate these system chambers into the climatic Laboratory, the new chambers have been assigned Environmental Chamber (EC) numbers. Numbers assigned to the nine chambers run sequentially from EC-188 through EC-196. This numbering scheme is introduced here because figures presented in much of the following text will show these EC numbers (i.e.,

Figure 3.7 ). 


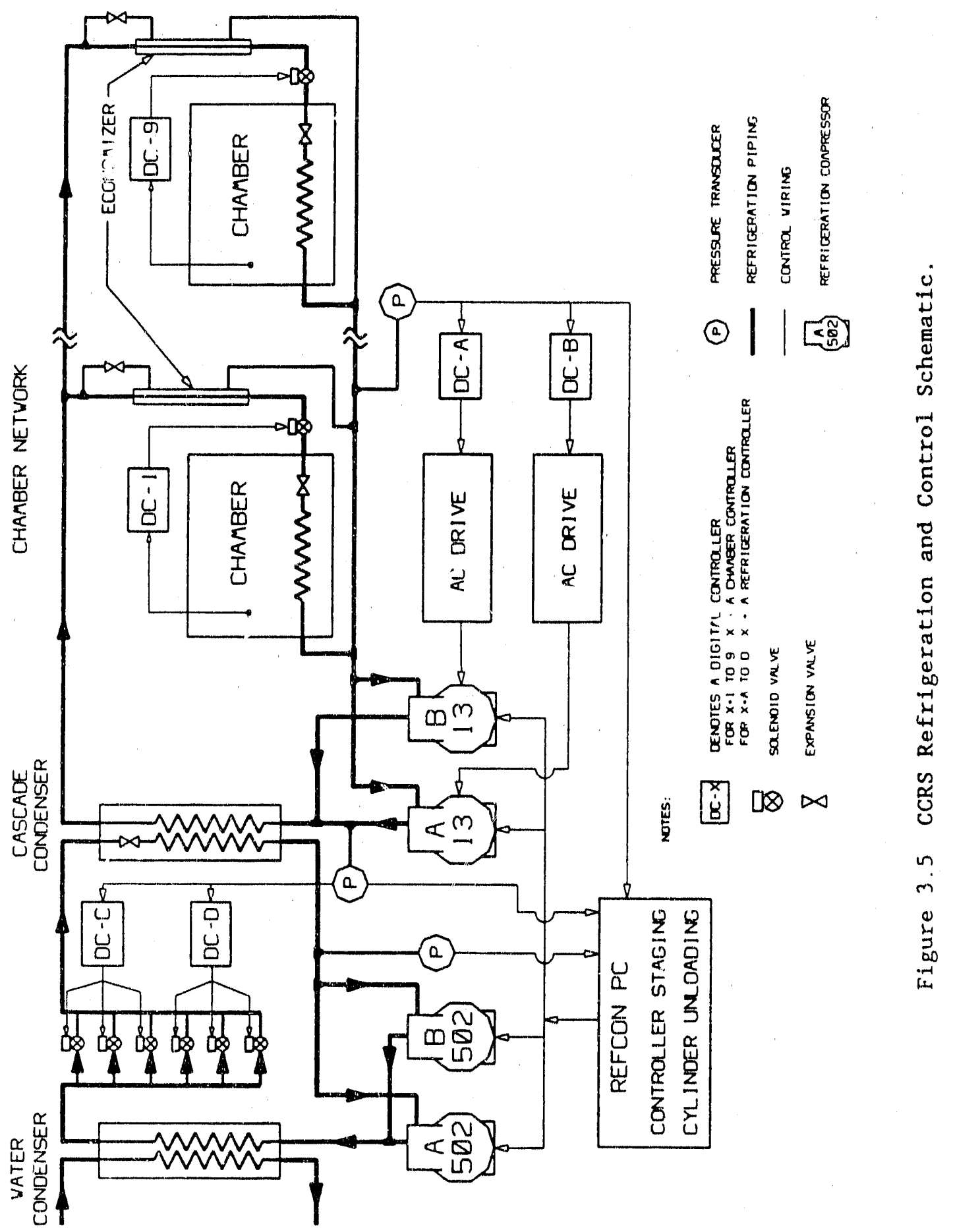




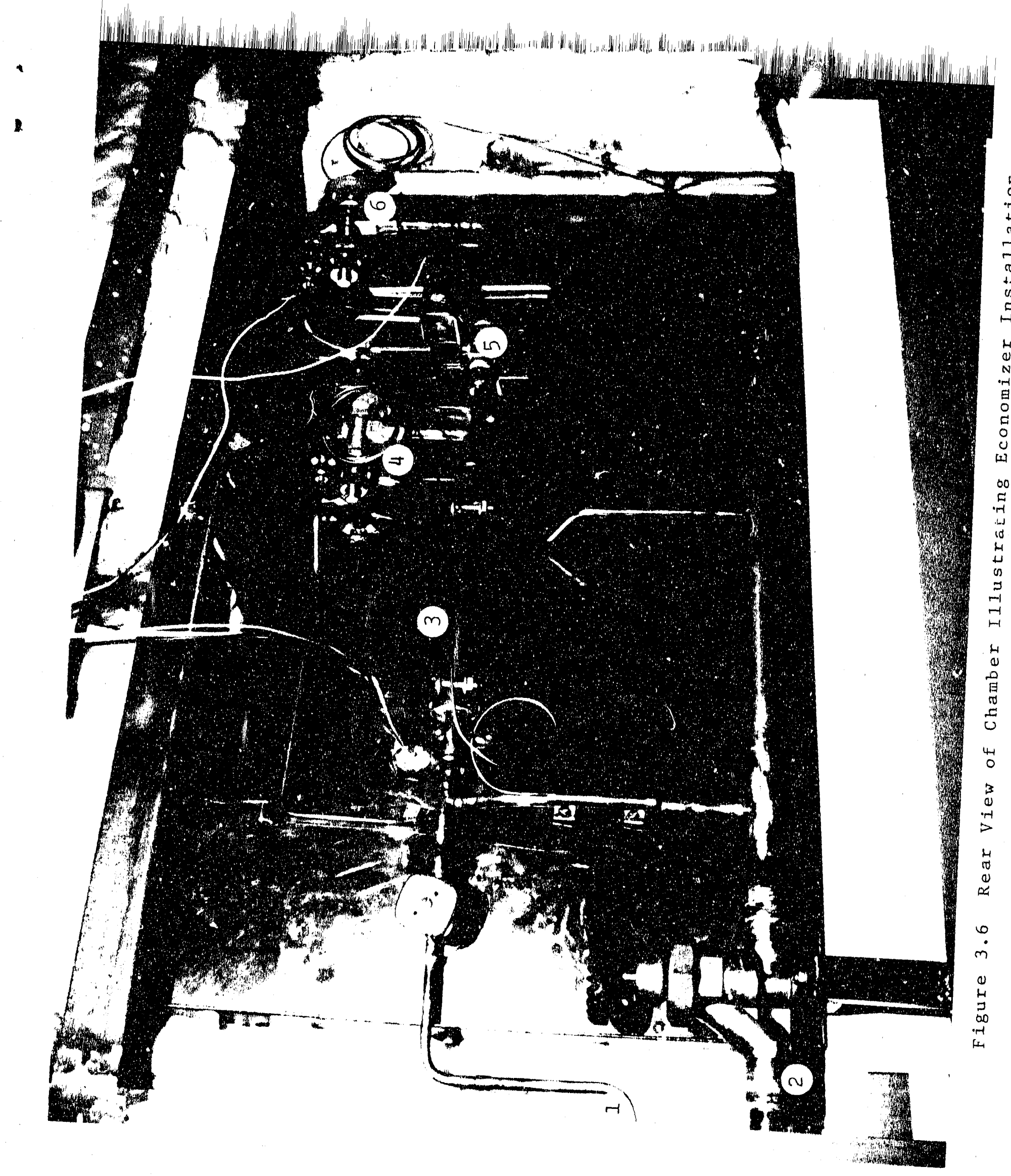




\subsection{Electrical Installation}

The CCRs electrical system can be segregated into two parts; electrical power and control circuitry. The discussion given in this section of the report is primarily concerned with electrical power hookups to major components. The control circuitry is discussed in the CCRS Control system section.

A diagram of the electrical power distribution for the CCRS is presented as Figure 3.7. All power (480 volts, 3-phase) is distributed from a main load panel with 14 circuit breakers; each breaker is designated for one of 14 circuits that supply power to the following:

1. compressor motor (25 HP), four each, 480 volts, 3-phase, 31 amps

2. small environmental chamber (2.2 $\mathrm{KW}$ heaters), four each, 240 volts, 10 amps

3. medium environmental chamber ( $8.5 \mathrm{~kW}$ heaters), four each, 480 volts, 3-phase, 11 amps

4. large environmental chamber (20 KW heaters), one each, 480 volts, 3-phase, 23 amps

5. ancillary electrical equipment ( $1 \mathrm{KW}), 120$ volts

(An exception is the power for the two control computers, which is supplied from an uninterruptible power source.)

Control of the electrical power to the motors is either by remote operating starters (for high stage $R-502$ units) or by Allen-Bradely AC motor drives (low stage $R-13$ units). Control of power to the chamber heaters is accomplished by SCRs as mentioned previously. 


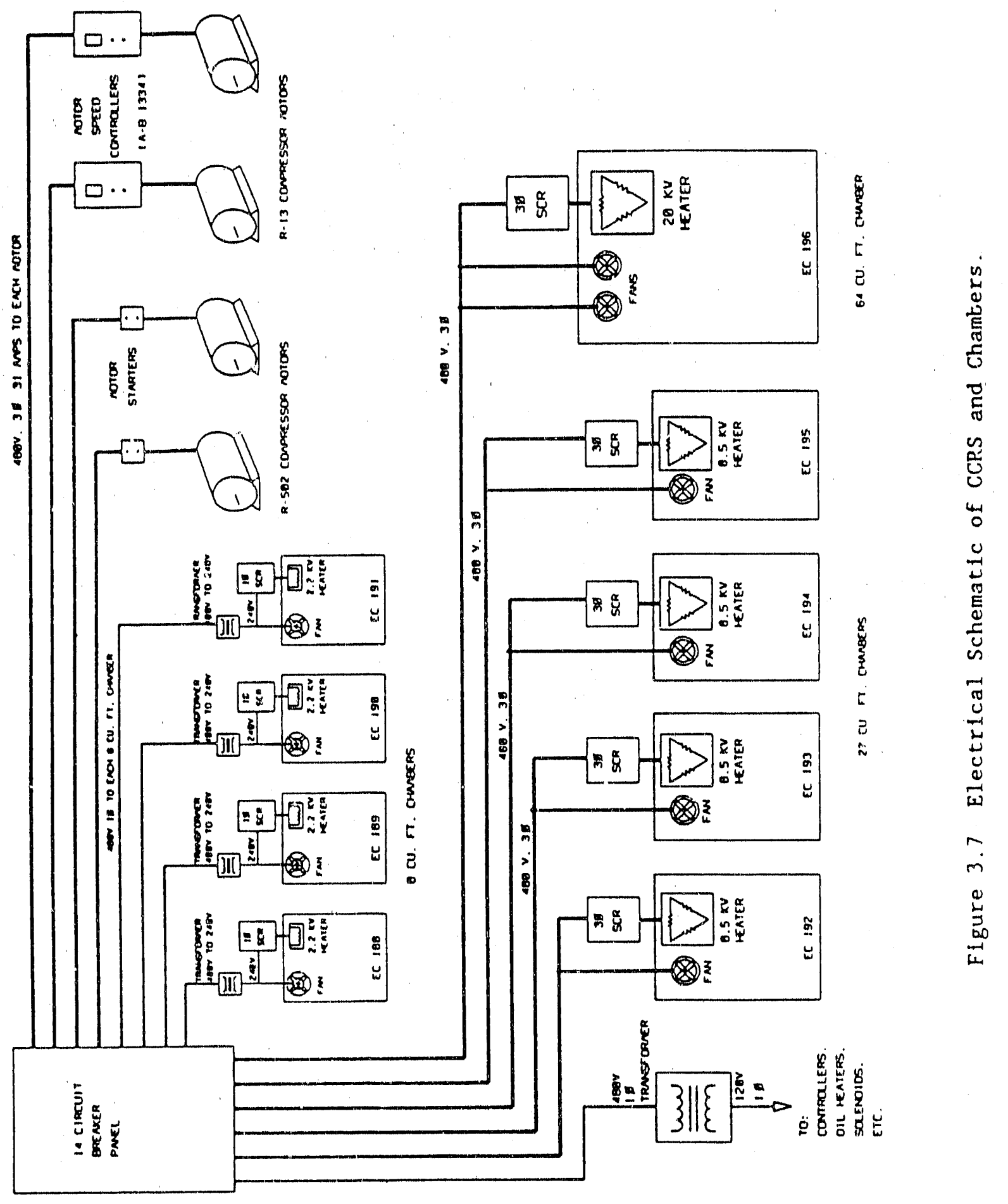




\section{O CCRS CONTROL BYBTEMB}

Chamber networking, in itself, does not increase the refrigeration system efficiency if the refrigeration system is designed to meet the worse-case cooling rate. Compressor false loading would still be required if most of the chambers on the network were at a steady-state environment (which has a high probability of occurrence). Availability of relatively lowcost, digital electronics facilitated the development of a unique refrigeration control system allowing the CCRS to effectively eliminate compressor false loading by varying compressor output according to the total network cooling demand [4].

\subsection{Background}

The control system used for a cascade refrigeration system, and the temperature chamber, is comprised of several feedback control systems. The key elements of a single variable feedback control system are shown in Figure 4.1 . The process variable (PV) is the controlled variable, i.e., the air temperature in a chamber at a particular time. The setpoint (SP) is the desired value for the process variable at any given time. The controller uses the "feedback" of the process variable to determine the difference, or error, from the setpoint $\left(E_{c}=S P-P V\right)$ and senerates an output signal. The magnitude of the output signal determines what corrective action will be used by the actuator to minimize the controller error, $E_{c}$, for the process or system. For temperature control, the range of the output signal is divided into two equal segments, one for heating and the other for cooling. This type of control system, where two actuators affect one process variable, is called duplex control.

For a conventional (stand-alone) chamber, there are three separate feedback control systems as shown in Figure 3.2 - one for the water condenser on the R-502 stage, olle for false loading each compressor, i.e., suction pressure control, and one for air temperature control in the chamber test volume. Each compressor in a conventional cascade system is operating at full speed and must be false loaded to maintain the nominal suction pressure operating conditions shown in Table 4.1 for each stage of the cascade (high temperature, $\mathrm{R}-502$ and $10 \mathrm{w}$ temperature, $R-13$ ). The $R-502$ water-cooled condenser maintains constant $R-502$ discharge pressure by using the discharge pressure to modulate a pressure-actuated water control valve. 
SET POINT (SP)

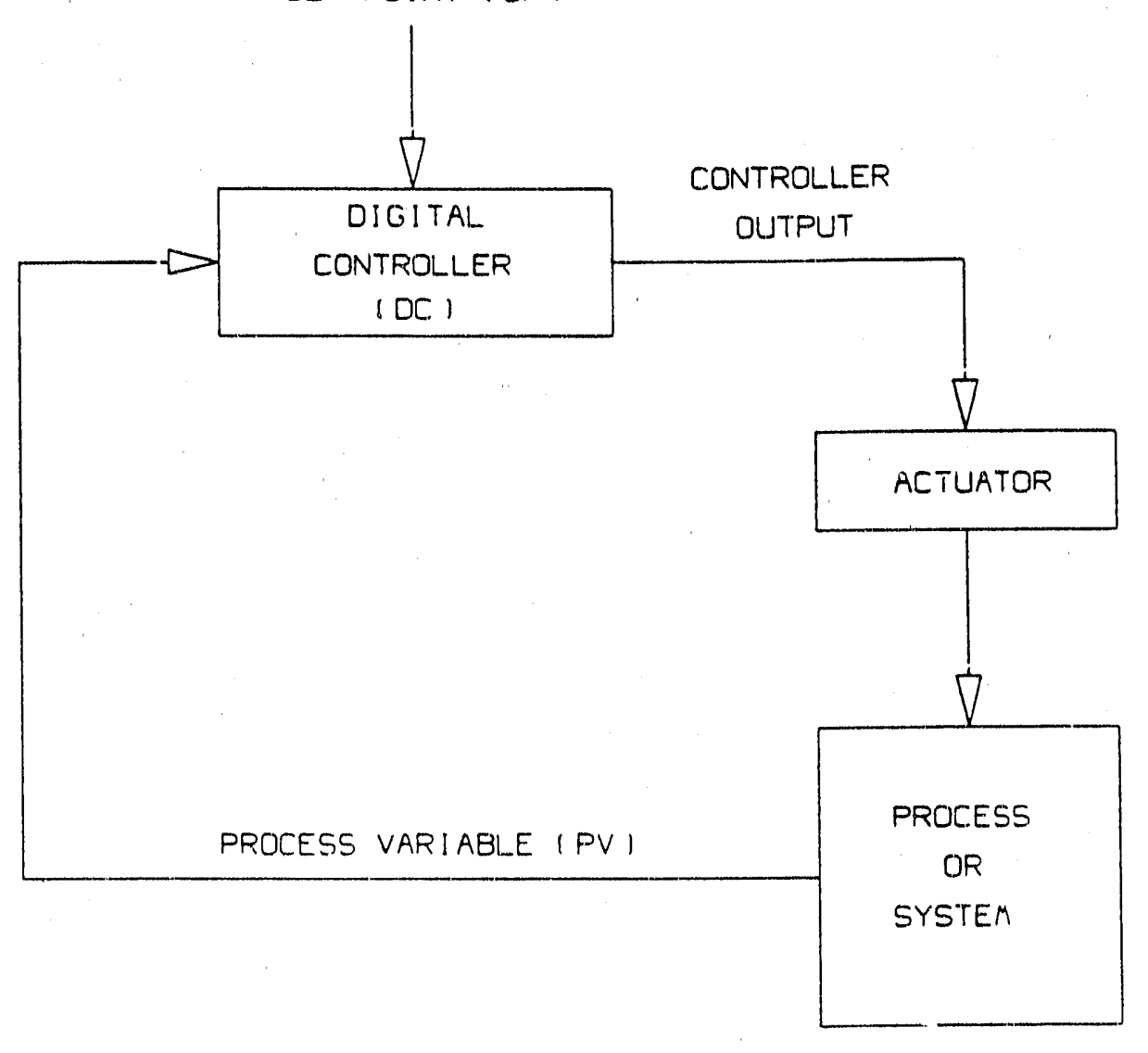

Figure 4.1 Simple Feedback Control system 


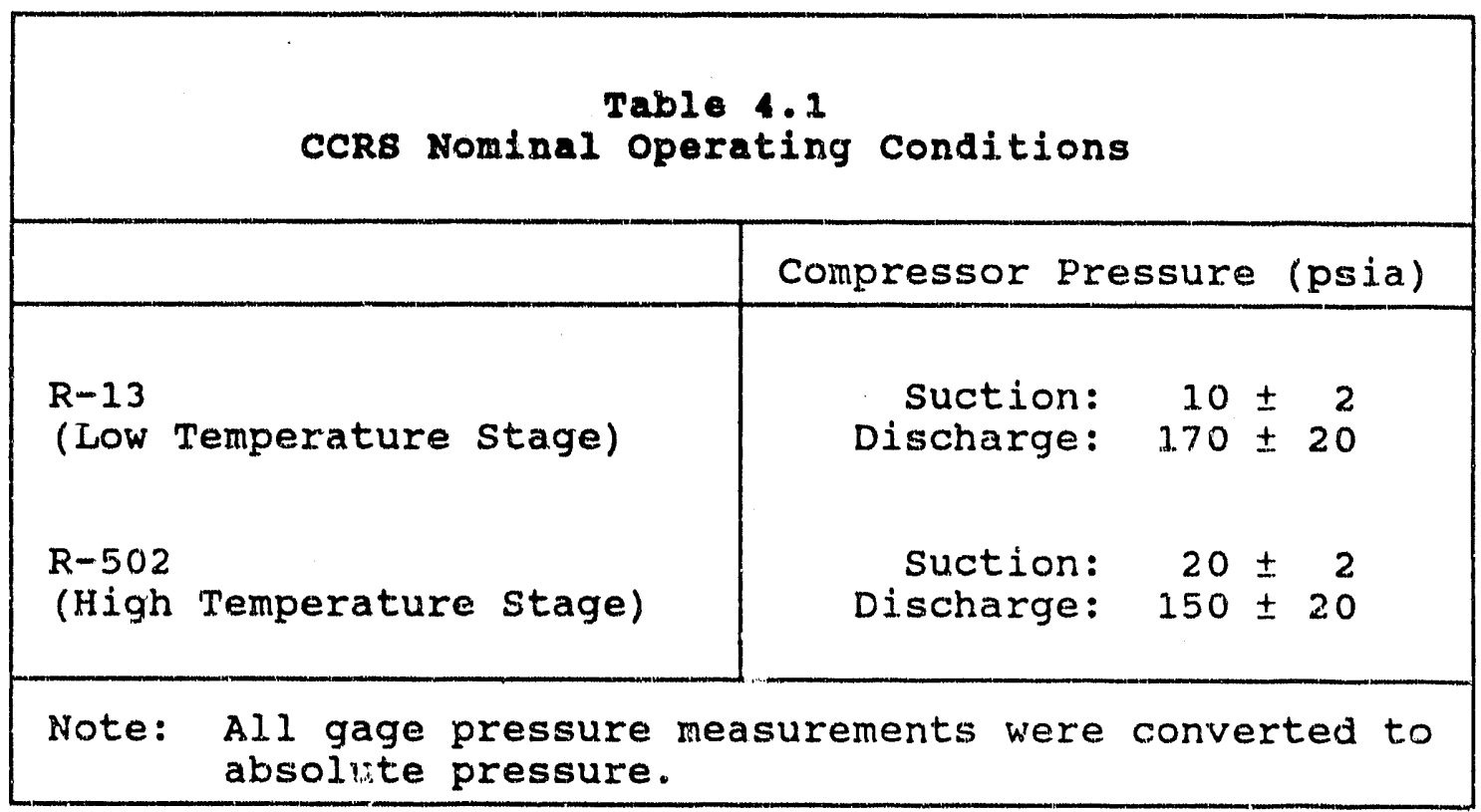

Both the false loading and water condenser control systems are mechanical, single actuator control systems. The false loading circuit on each temperature stage ensures a minimum suction pressure while the condenser control circuit ensures a minimum R-502 discharge pressure. There is no control on the $R-13$ discharge pressure. The chamber air temperature circuit is a duplex output feedback control system. The digital controller (DC) actuates the cooling solenoid (liquid refrigerant to evaporator) or the SCR (heaters) depending on the magnitude of the controller output signal.

In contrast to conventiona chambers, the control system for the CCRS outlined in Figure 3.5 is much more complex. The false loading control system has been replaced with the compressor output control system. In addition to the R-502 condenser control system, a single actuator feedback control system was added to the cascade heat exchanger ( $R-13$ condenser).

The CCRS operates continuously to respond to requests for cooling from any chamber on the network. To avoid the possibility of a chamber control malfunction affecting the CCRS, two separate control systems were developed for refrigeration and environmental chamber temperature control. 


\subsection{CCRs Refrigeration Control}

The central element of the refrigeration control system is the PC shown in Figure 4.2, which executes a BASIC computer program titled REFCON [5]. REFCON controls the R-502 (high temperature stage) and $R-13$ (low temperature stage) compressor output. cascade heat exchanger output, and redundant compressor startup for additional compressor capacity. A component diagram of the CCRS control system is shown in Figure 4.2. The R-502 watercooled condenser control system (shown in Figure 3.2) is the only control system carried over from the standard cascade refrigeration system. In addition to REFCON, there are two separate control systems to vary the $R-13$ compuessor speed and the cascade condensing capacity. Both of these control systems utilize the digital controllers shown as DC-A through DC-D in Figure 4.2 to maintain the nominal operating pressure conditions specified in Table 4.1. The output of each digital controller can be overridden by REFCON to allow for redundant compressor startup. When referencing Figures 3.5 and 4.2 , the "A" System refers to the compressor system that is alway's operational, and the "B" system refers to the redundant (idle) compressor system. In actual practice, the "A" and "B" systems are switched (where "B" now operates continuously) every month to allow for equal wear on both compressor systems.

\subsubsection{Compressor capacity Control}

At any given time, each chamber connected to the CCRS can be simulating a different temperature environment. Therefore, the total chamber demand (refrigeration load) can be constantly changing with respect to time. Given that all nine chamber evaporators are common to the same suction line, the $\mathrm{R}-13$ suction pressure, which depends on the total chamber demand, must not be allowed to fluctuate more than 5 psi to avoid losing temperature control in any one of the chambers (as discussed in saction 4.3). To match the compressor output to the chamber demand, an $A C$ drive is used to vary the $R-13$ compressor speed in response to fluctuations in the $\mathrm{R}-13$ suction pressure. In Figure 3.5, the digital controller shown as $D C-A$ for compressor $A$ (or $D C-B$ for compressor $B$ ) generates an output signal that is proportional to the errox between the measured $R-13$ suction pressure and the desired pressure (setpoint) shown in Table 4.1. Depending on the magnitude of the output signal, the $A C$ drive effectively varies the compressor output at a rate of $6 \mathrm{cFM} / \mathrm{sec}$. from $23 \%$ (speed $=400$ rpm) to $100 \%$ (speed $=1750 \mathrm{rpm}$ ). As the chamber cooling demand increases, the $\mathrm{R}-13$ suction pressure increases and the $\mathrm{AC}$ drive responds by accelerating the compressor motor to increase the compressor output. Note the compressor output in CFM is 


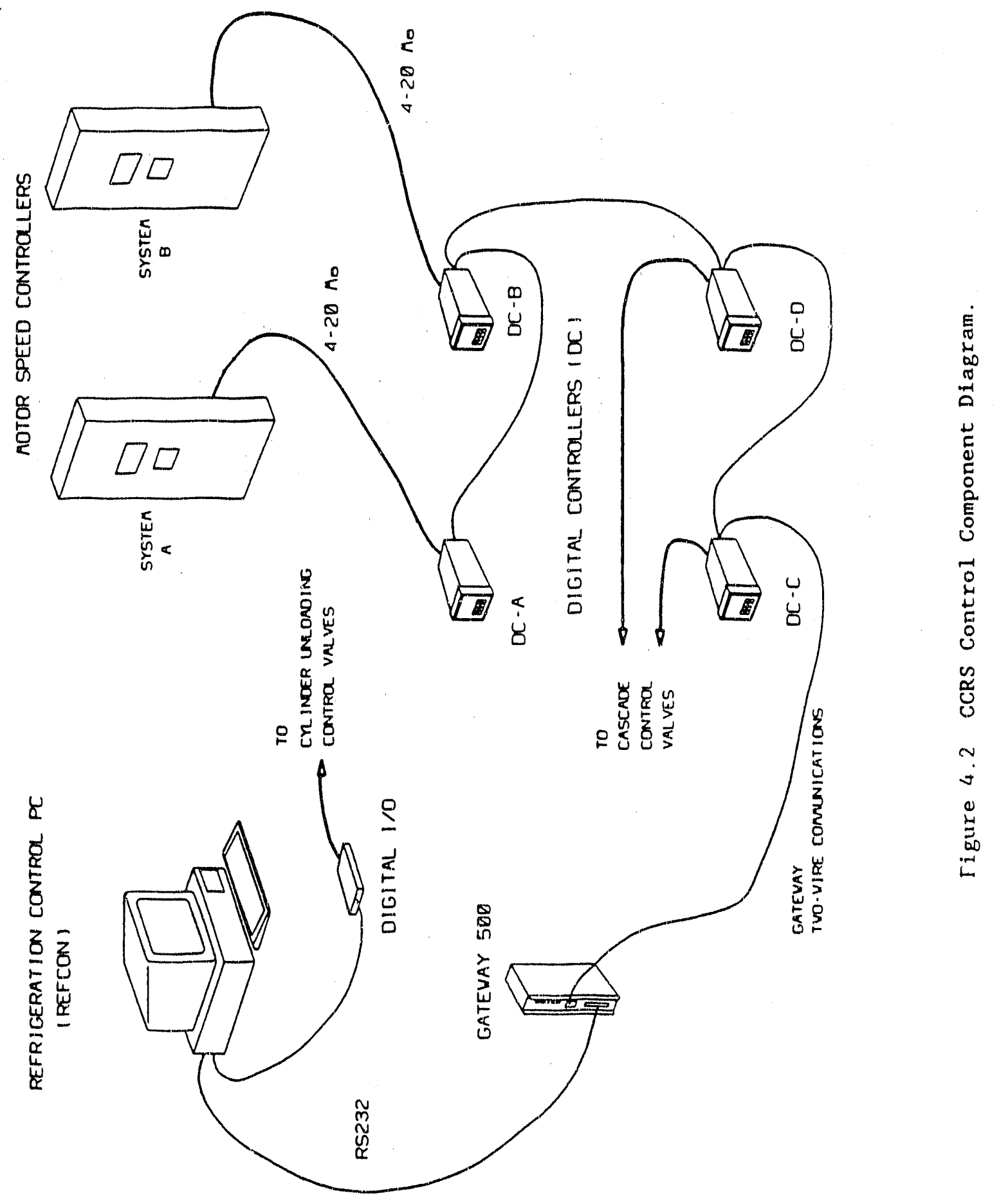


computed by simply multiplying the compressor output (\%) by the compressor capacity of 60 CFM.

The minimum compressor output of $23 \%$ corresponds to a compressor speed of $400 \mathrm{rpm}$, which is needed to guarantee that cylinders will not inadvertently unload due to insufficient oil pressure. If the compressor is operating at minimum speed and the $\mathrm{R}-13$ suction pressure is still decreasing, REFCON holds the compressor speed at $400 \mathrm{rpm}$ and unload compressor cylinders one at a time to decrease the compressor output from $23 \%$ to $7.8 \%$ in $3.8 \%$ increments. REFCON verifies that the compressor is at minimum speed before determining if a fluctuation in the suction pressure warrants loading or unloading a compressor cylinder. By using cylinder unloading when the compressor is operating at minimum speed, the compressor output is reduced by $3.8 \%$ increments instead of the $16.7 \%$ increments dictated by the maximum compressor speed of $1750 \mathrm{rpm}$. If the output of compressor $A$ is $100 z$ and the absolute suction pressure increases above 27 psia, REFCON starts up the redundant $R-13 \mathrm{~B}$ compressor to provide additional capacity to meet the peak chamber demand. During redundant startup, the $R-13$ compressor capacity jumps from $100 \%$ to $107.8 \%$ because the $B$ compressor speed starts at $400 \mathrm{rpm}$, with four cylinders unloaded, while the A compressor is forced to operate at full speed. REFCON forces the A compressor system to operate at full speed whenever the $B$ compressor system is controlling the $R-13$ suction pressure. It is important to minimize the disturbance to the $R-13$ suction pressure to avoid potential oscillations caused by the response of the control system trying to reach the desired pressure setpoint. Large increases in compressor capacity immediately reduce the suction pressure (and the evapcrator temperature), which may cause an undesirable temperature fluctuation in any of the chambers that are being cooled.

The refrigeration demand on the high temperature stage $(R-502)$ of the CCRS depends on the quantity of R-13 discharge vapor (from the low temperature stage), which must be condensed in the cascade heat exchanger. As such, the $\mathrm{R}-502$ suction pressure should not exceed $37 \mathrm{psia}$, which corresponds to a cascade temperature of $0^{\circ} \mathrm{F}$. The minimum suction pressure should never drop below 0 psig to avoid drawing moisture or other contaminants into the refrigeration system. Since the allowable fluctuations in suction pressure for the high temperature stage $(R-502)$ are much larger than the low temperature stage ( \pm 15 psi compared to \pm 5 psi for the $R-13$ ), and the cascade heat exchanger responds slowly (very large thermal mass), only cylinder unloading without compressor speed control is used to vary the $R-502$ compressor output. REFCON operates cylinder unloading on the high temperature stage in the same manner as the low temperature stage $(R-13)$, except 
that the $R-502$ suction pressure is the control variable and the R-502 compressor output is limited to five operating points: $100 \%, 83 \%, 67 \%, 50 \%$, and 33\%. If the R-502 suction pressure exceeds 37 psia, REFCON starts up the R-502 B compressor for additional capacity. Note that for this case, the minimum R-502 compressor capacity would be 133\%. Some false loading of the R-502 compressor is required when the $\mathrm{R}-13$ compressor output is below $30 \%$, which could occur if no chambers on the network. required refrigeration (e.g., no chamber load).

\subsubsection{Cascade Heat Exchanger Control}

The lag time required for the high temperature stage $(R-502)$ to respond to a sudden increase in the chamber demand is long enough for the cascade to lose the capability to condense all the R-13 vapor. This results in loss of chamber temperature control. The thermal delay is caused by the large thermal mass in the cascade. (i.e., a tube within a tube heat exchanger) necessary to meet the capacity of the low temperature stage compressor.

For stand-alone systems, the loss of temperature control is mitigated by keeping the refrigeration system operating for a fixed period of time in the absence of any cooling demand. In the event the demand for cooling is fluctuating on and of $f$, the refrigeration system is operational, avoiding the lag time associated with start up.

In order to utilize the compressor unloading features of the high temperature stage on the CCRS, an additional control system was implemented to maintain a constant $\mathrm{R}-13$ discharge pressure by varying the amount of $R-502$ liquid expanded in the cascade (R-502 evaporator). Fluctuations to the $R-13$ discharge pressure are caused by control adjustments to the $\mathrm{R}-13$ compressor to meet the cooling demand. Accordingly, the $\mathrm{R}-13$ discharge pressure can be used to detect changes in the cooling demand, which determines how much of the available cascade capacity should be used.

The digital controller shown as DC-C in Figure 3.5 opens or closes one of three staged-control valves depending on the value of the $\mathrm{R}-13$ discharge pressure. A staged-control valve implies that only one of the six available valves is controlled. If the demand requires between one and two valves to be open, the first valve remains open $100 \%$ and the second valve is open (controlled) for $50 \%$ of the time. In the event the R-13 discharge pressure continues to increase after the output of DC-C reaches $100 \%, D C-D$ is enabled in the same manner as DC-C to provide the additional cascade condensing capacity required to maintain control of the $R-13$ discharge pressure. Note that REFCON locks the output of DC-C at $100 \%$ whenever DC-D 
is enabled. The cascade control system affects control of the R-502 compressor in the same manner as the temperature chamber affects the control of the R-13 compressor. When a solenoid on the cascade is actuated or disabled, the $\mathrm{R}-502$ suction pressure increases or decreases accordingly. The use of a staged cascade gives much better control of the available condensing capacity by improving the response of the high temperature stage $(\mathrm{R}-502)$ compressor system to abrupt changes in the chamber demand for cooling.

\subsection{Environmental Chamber control}

Each chamber on the network is equipped.with a digital controller for the purpose of temperature control. As such, each chamber can be controlled independently as if it were a stand-alone chamber. If one digital controller becomes inoperable, it does not affect the controllers of other chambers. An advantinge of using a digital controller is that a PC can be used to record the setpoint and process variable along with the controller output. This information is critical to evaluating the CCRS because the chamber demand, along with the chamber response, can be compared directly to the response of the CCRS. Other advantages of using digital controllers include the ability to control the chamber from a remote location and to monitor ongoing tests.

From the perspective of chamber temperature control, the only operational difference between the CCRS and a typical standalone chamber is that the cooling solenoid draws liquid refrigerant from a common supply line connected to all chambers in the network instead of a supply line and associated refrigeration system dedicated to just one chamber. In the event of a shortage of liquid R-13 refrigerant, the chamber controller increases the output signal to keep the cooling solenoid open longer in an attempt to maintain the desired chamber temperature. As the supply of liquid refrigerant increases, the larger evaporators (which have lower pressure drops) obtain a disproportionate share of the available refrigerant. The CCRS must always maintain a sufficient supply of liquid refrigerant to avoid losing temperature control in any of the chambers in the network. By definition, a standalone chamber never has to share liquid refrigerant. As the refrigeration system begins to meet the demand, the stand-alone chamber regains temperature control.

The major components used in the chamber control system are shown in Figure 4.3. The two BASIC programs, SUPERHOST and SUPERCON $[5,6]$, are executed on the Host and the chamber Control PC, respectively. SUPERHOST gives the operator the 


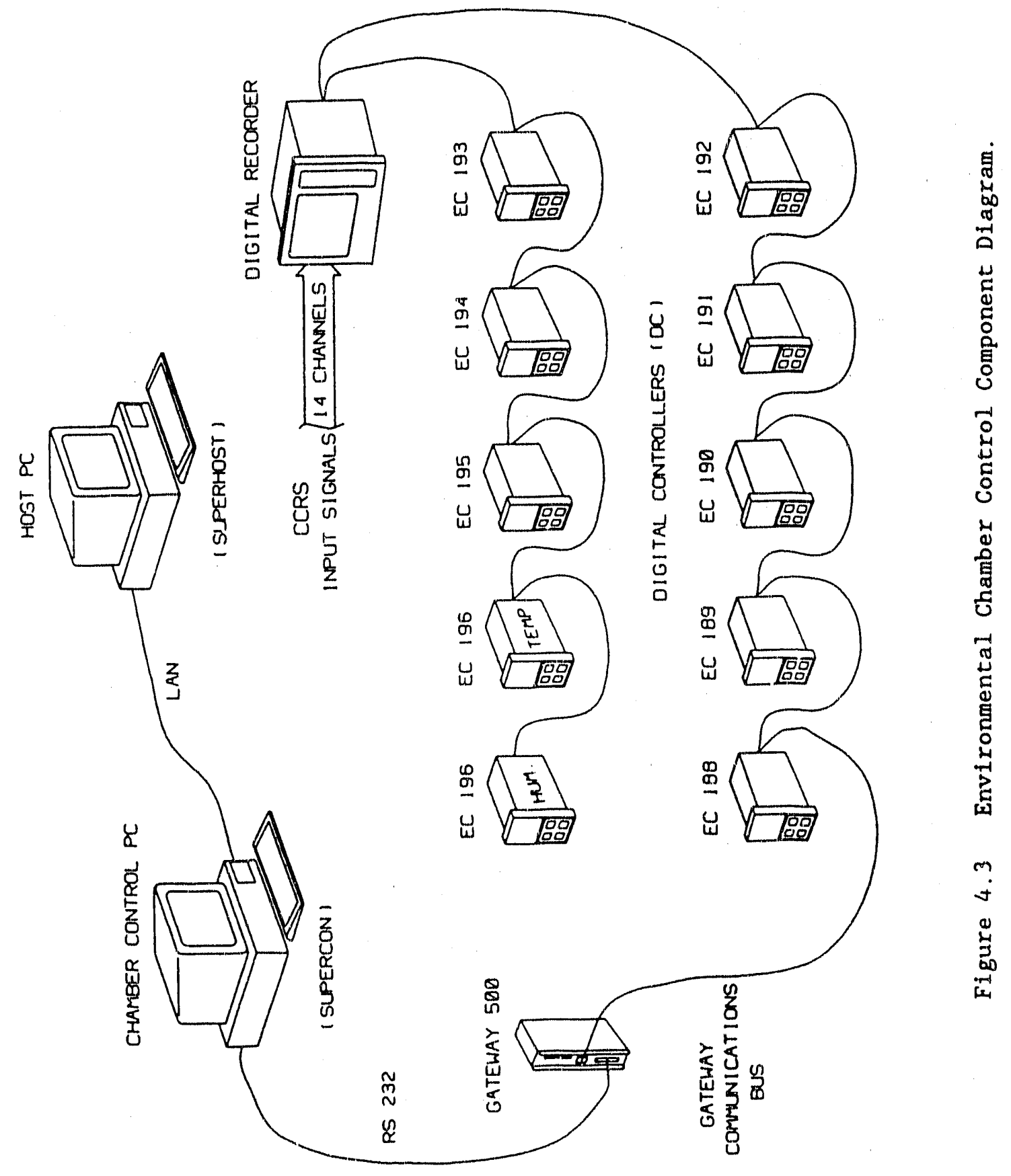


capability to specify (input) a temperature profile 1 , transfer the information to a specific chamber controller, start or stop a chamber, monitor chamber information (temperature, setpoint, or controller output), ior log any relevant CCRS information. SUPERHOST communicates with SUPERCON across a Local Area Network (LAN), which connects the Host and Chamber control PCs. SUPERCON, in turn, communicates with the chamber digital controllers through a RS-232 serial data link to the Honeywell Gateway 500. The Gateway 500 is an interface, which networks the chamber control PC to the nine chamber temperature controllers (up to a maximum of 30) and a Honeywell DPR-1500. The DPR-1500 is used to gather real-time information on CCRS (refrigeration pressures, oil pressures, etc). SUPERCON automatically stores the current value of all controller and DPR-1500 variables on the Host PC via the LAN.

SUPERCON normally sends the entire time/temperature profile for a particular test to the controller. In the event the temperatuie profile requires more than 20 segments (i.e., the maximum allowed for these controllers), SUPERCON downloads information to the controller in supervisory mode. In the supervisory mode, SUPERCON runs in a continuous control loop providing updated setpoint information to the controller based on the temperature profile. SUPERCON's continuous control loop takes about four seconds to complete, meaning that in the supervisory control mode a setpoint can be updated about every four seconds. The supervisory control mode also allows the flexibility of generating complicated temperature profiles including sine wave and diurnal profiles.

Consideration was given to cominining SUPERHOST and SUPERCON into one program, thereby, eliminating the need for two separate PCs. This would require that SUPERCON execute continuously in "Background Mode", while SUPERHOST is interfacing with the operator. "Background Mode", in this context, implies that SUPERCON would concurrently share the available execution time with suPERHOST. The operating system (Microsoft DOS 3.3) used on the IBM AT compatible PC is not well suited for this type of multi-tasking.

Note the addition of the Host PC eliminates the need for temperature recording instruments at every chamber because all the chamber temperatures can be recorded onto the Host PC hard disk.

Communications between SUPERHOST and SUPERCON are simplified by the use of a LAN. The LAN is manufactured by Invisible Network, Inc. [7], and utilizes both hardware and software.

1- EC-196 has the added capability of simulating humidity enviroments. A digital controller is used to control the humidity process in the same manner as the air temperature. 
The hardware necessary to connect the Chamber Control and Host PCs consists of a network adapter inserted into a 16-bit expansion slot on each networked $P C$, and an unshielded twisted pair cable terminated by RJ-11 connectors. Communication across the LAN is controlled by software, which resides on both PCs. The LAN is capable of transferring data across the link at 3.0 Mbps (million-bits per second). The technique of "Heartbeat Collision Avoidance" is used by the network software to control communications over the network link. This technique relies on the fact that each PC on the network transmits information in packets. The network polls each PC allowing it to transmit a packet. When one PC has finished sending its packet, the next PC in the polling sequence is allowed to send one of its packets. Only one PC is allowed to use the LAN at any one time. The LAN software automatically queues the data waiting to be sent from each PC so that information is not lost while waiting for the next poll. Because data can be transmitted at $3.0 \mathrm{Mbps}$ and the network manages the transmission by allowing data to be queued, a struggle for communication time by any one PC is prevented.

There are two main files located on the Host PC, that are accessed by both SUPERHOST and SUPERCON. These files are used for transferring directives and responses between the two computers (i.e., allowing both PCs to communicate). Each PC writes commands to one file and reads responses/s from the other file. Using this scheme eliminates the contention of SUPERHOST and SUPERCON trying to write to the same file at the same time. To prevent SUPERCON from accidentally executing the same command (i.e., downloading a temperature profile) for every control loop, SUPERHOST places a random number as a header to the file being written. SUPERCON compares the previous number from the last read and takes no action if the numbers are the same (indicating that the information has not changed since the last read).

The Environmental Chamber Control system not only manages the remote programming of environmental chambers, but also provides a means, by which, evaluation information can be gathered. Communications between the two AT-class computers are handled exceptionally well. with the use of a commercially-available LAN. 


\subsection{EVALUATION PROCEDURE}

The objectives of the evaluation were to determine if the design criteria had been satisfied, and to compare the performance and efficiency of the CCRS to a conventional standalone chamber. A temperature profile between $165^{\circ} \mathrm{F}$ and $-65^{\circ} \mathrm{F}$ with a 4-degree $\mathrm{F} / \mathrm{min}$. Iinear ramp xate, hereafter referred to as RAMP4, was selected to evaluate the performance of the CCRS. The RAMP4 profile shown in Figure 5.1, typifies requirements to simulate extreme climatic environments. The following text describes how data are acquired and used to verify the performance of the CCRS.

Both the temperature setpoint and the chamber air temperature are monitored by the Chamber control PC (SUPERCON) to ascertain if the chamber is within allowable temperature control tolerances during chamber operation. Additionally, the temperature setpoint can be used to compare the response of the CCRS to the chamber demand. All the CCRS pressure control variables listed in Table 4.1 and compressor oil pressures were also monitored by SUPERCON via the DPR-1500 (refer to section 4.3). The output signals from controllers DC-A through DC-D and the number of compressor cylinders, which are operating on each comprussor (i.e., loaded), were monitored by REFCON during evaluation of the CCRS. The compressor speed is inferred from the controller output (either DC-A or DC-B) signal

(min. output $=\min$. speed). The compressor output, CompouT, was estimated using the following relation:

$$
\text { COMPOUT }=\frac{(C S)}{1750} *(100 t) ; 400<C S<1750
$$

or

$$
\text { COMPOUT }=\frac{N C L}{6} *(23 \%) ; C S=400
$$

where

$$
\begin{aligned}
C S & =\text { compressor speed, rpm; DC-1 output signal } \\
\mathrm{NCL} & =\text { number of operational cylinders }(2 \text { to } 6)
\end{aligned}
$$

Equation (1) applies when the compressor motor speed is controlled to vary compressor capacity, and Equation (2) applies when cylinder unloading is used to vary compressor capacity. Accordingly, the $\mathrm{R}-13$ compressor output range is from $7.8 \%$ to $100 \%$ for one-compressor operation, and $107.8 \%$ to $200 \%$ for two-compressor operation. Since only cylinder unloading is used to vary the output of the $\mathrm{k}-502$ compressors, the compressor output is $1 / 6$ the number of cylinders that are operating. Therefore, the R-502 output range for onecompressor is between 33.38 (two of $\mathrm{six}$ cylinders operational, 
four cylinders unloaded) to $100 \%$ and for two-compressor operation, the range is $133.3 \%$ to $200 \%$. The CFM output of a compressor is determined by multiplying COMPOUT by $60 \mathrm{CFM}$. The cascade condensing output is simply the sum of controller output signals from DC-C $(0-100 \%)$ and $D C-D(0-100 \%$ when applicable) so the output range varies between $0 \%$ and $200 \%$ (i.e., the cascade is sized for two-compressor operation). Duririg an evaluation test, the timebases on both REFCON and SUPERCON are synchronized so that the data gathered can be compared directly.

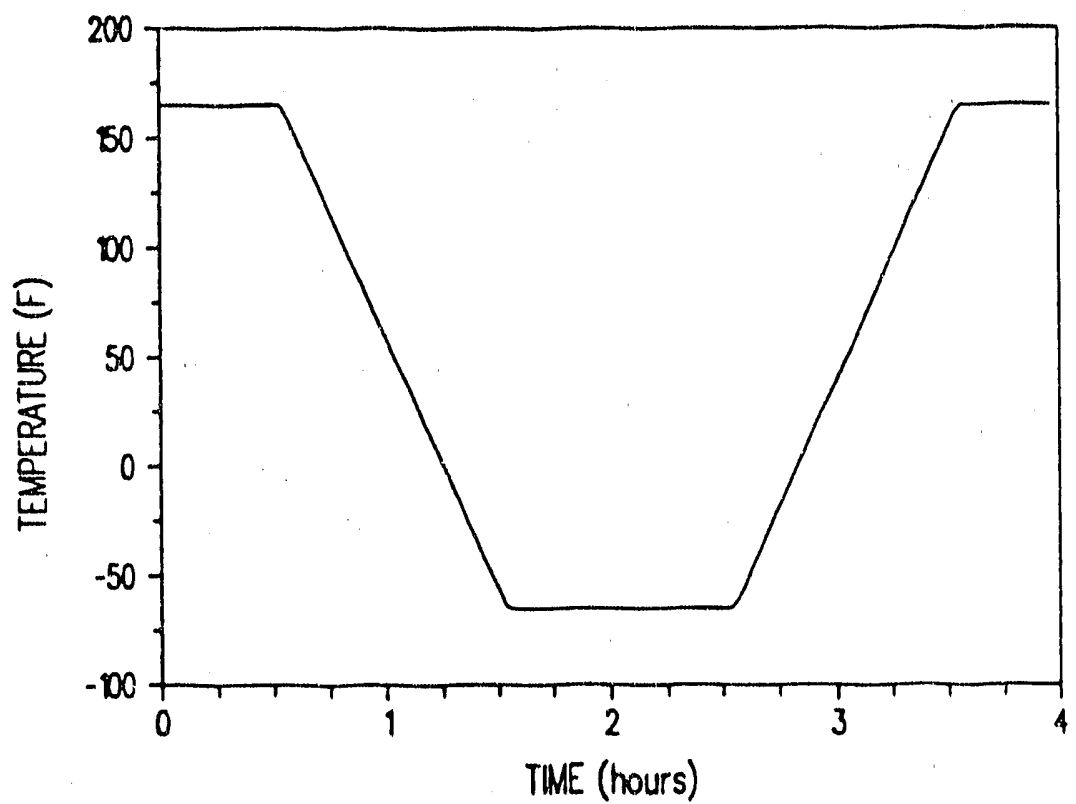

Figure 5.1 Ramp4 Temperature Profile 


\subsection{CCRS PERFORMANCE AND EVALUATION}

\subsection{Costrol system Performance}

The important cCRs design objectives are to provide an adequate supply of iquid $R-13$ for each of the nine chambers (irrespective of the total chamber demand), and reduce compressor false loading (improve efficiency). Unless specified otherwise, the response of the cuntrol system was assessed during the peak load condition where all the chambers were started simultaneously using the RAMP4 profile.

Compressor false loading is reduced during periods where the maximum refrigeration capacity is not needed to meet the demand for cooling from all nine chambers on the network. Figure 6.1 shows the variation in the $R-13$ compressor output required to maintain the $R-13$ suction pressure at 10 psi. The $R-13$ compressor output required to maintain all nine chambers at $-65^{\circ} \mathrm{F}$ is $50 \%$, while approximately $150 \%$ is needed during the simultaneous pull-down of all chambers simulating the RAMP4 cycle. If compressor false loading had been incorporated exclusively instead of controlling compressor output, both pairs of compressors would have been operating at capacity, i.e., $200 \%$ output, to meet the total chamber demand.

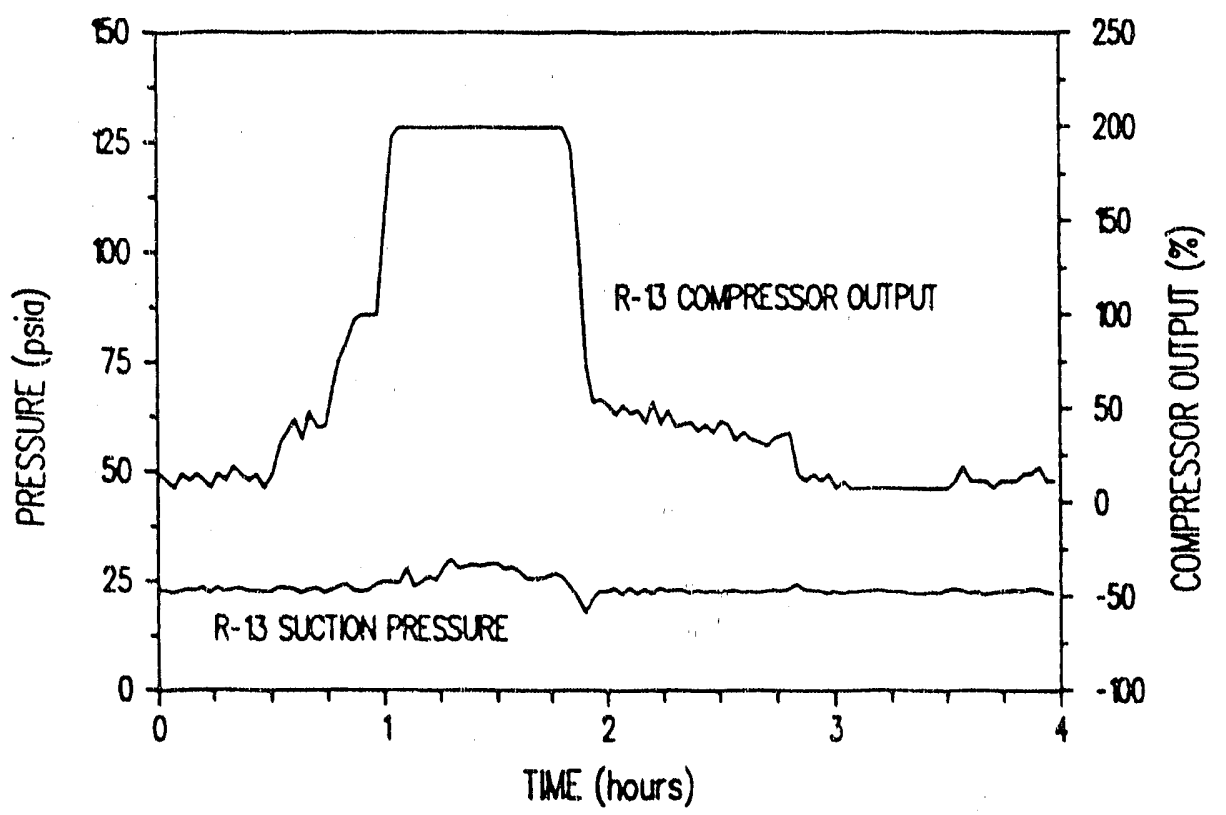

Figure 6.1 R-13 suction Pressure and Compressor output Response. 


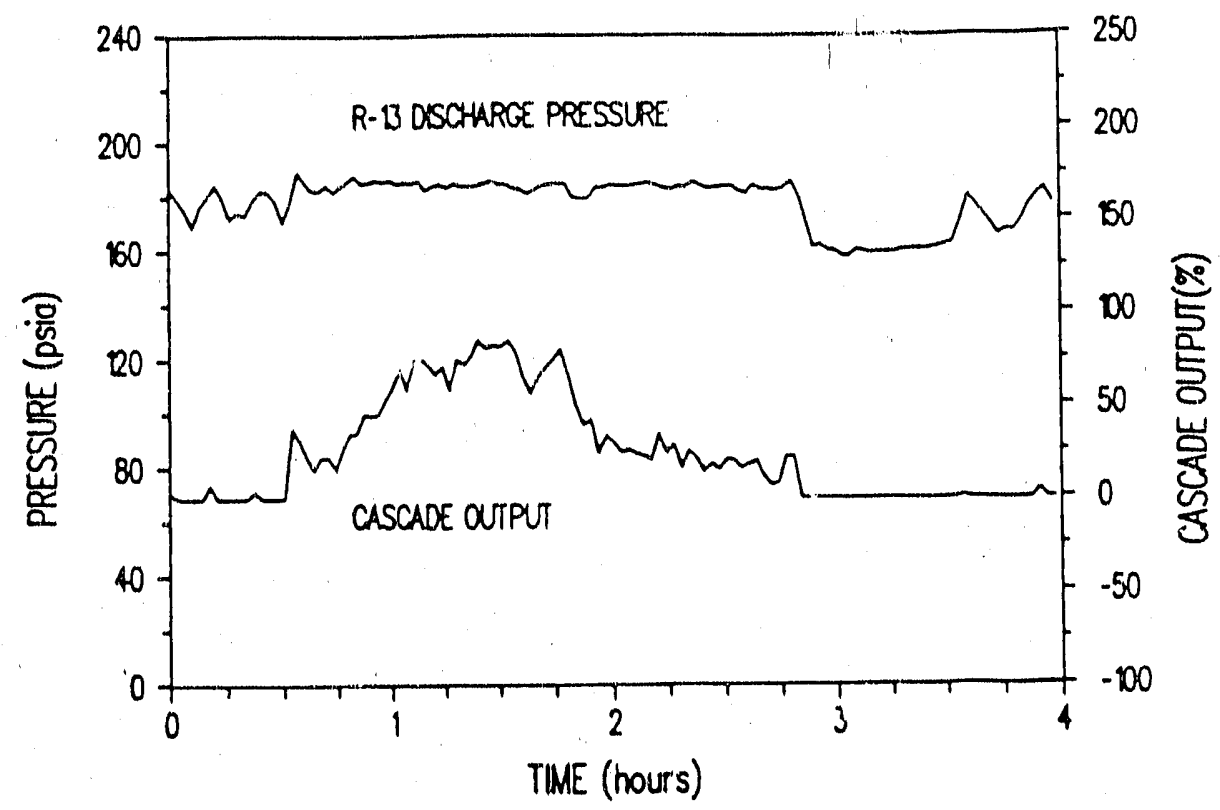

Figure 6.2 R-13 Discharge Pressure and Cascade output Response.

The response of the cascade to the $R-13$ cooling demand is shown in Figure 6.2 by comparing the $R-13$ discharge pressure and the cascade (condensing) output. The discharge pressure is controlled within \pm 10 psia during periods of cooling demand. There is no control of the $\mathrm{R}-13$ discharge pressure during the portion of the RAMP4 profjle when the cascade output is $0 \%$ (no demand for cooling). These discharge pressure fluctuations ( \pm 30 psia) have no effect on CCRS performance. During normal CCRS operation when various chambers are simulating different environments as opposed to the same temperature profile in each chamber, the cascade output is always nonzero.

The refrigeration load on the $R-502$ system is dictated by the cascade output. An increase in cascade output allows more liquid $\mathrm{R}-502$ to expand in the cascade, which causes an increase in R-502 suction pressure. Comparing Figures 6.1 and 6.2 ., the cascade output response lags the $R-13$ compressor output response during the RAMP4 cycle by less than one minute. The cascade responds immediately to any variation in the chamber demand.

Figure 6.3 shows the variation in the $R-502$ compressor output to control the R-502 suction pressure. Again, notice that the fluctuations in suction pressure are woll within the acceptable range to maintain adequate condensing capacity. When chamber 
cooling demand increases, the cascade output increases to counteract an increase in $\mathrm{R}-13$ discharge pressure. The $\mathrm{R}-502$ compressor output increases to maintain constant suction pressure (see Figure 6.3). The overall time required for the R-502 compressor to respond to a sudden increase in $R-13$ compressor output is less than one minute. The CCRS cascade control system essentially eliminates the thermal delay associated with sudden increases in cooling demand found in conventional cascade systems.

The chamber temperature setpoint is compared to the $\mathrm{R}-13$ compressor output in Figure 6.4 to demonstrate the responsiveness of the CCRS to a change in the cooling demand. Notice the immediate increase in compressor output when the temperature setpoint decreases. The quick response time of the CCRS to variations in the chamber cooling demand allows the compressor output to be controlled without sacrificing temperature control.

Figures 6.5 and 6.6 show the $R-13$ compressor response for both a conventional (stand-alone) chamber and the CCRS to the RAMP4 temperature profile, respectively. Observe how the discharge and suction pressures on the conventional chamber equalize when the refrigeration system is disabled during the heating portion of the RAMP4 profile. When the refrigeration system is enabled, there is at least a five-minute delay before any liquid refrigerant is actually cooling the chamber, as shown by the response of the suction pressure in Figure 6.7. 


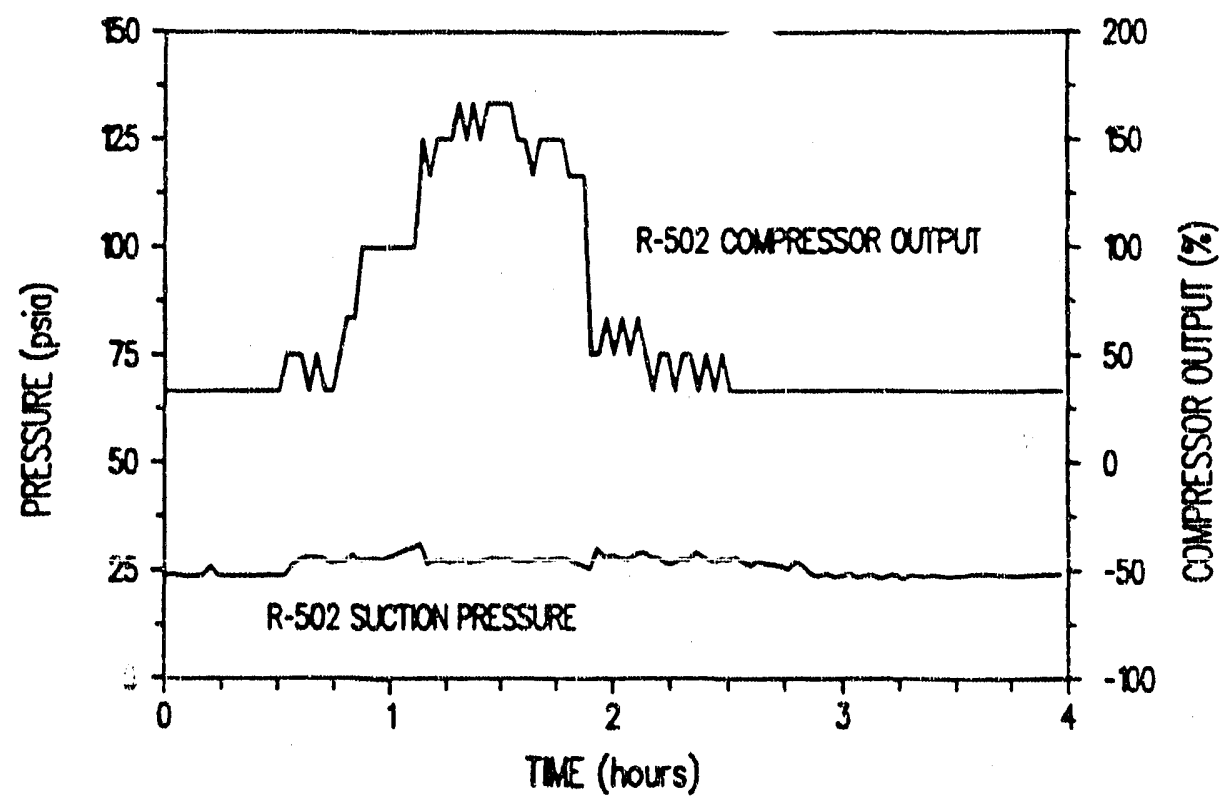

Figure 6.3 R-502 Suction Pressure and Compressor Output Response.

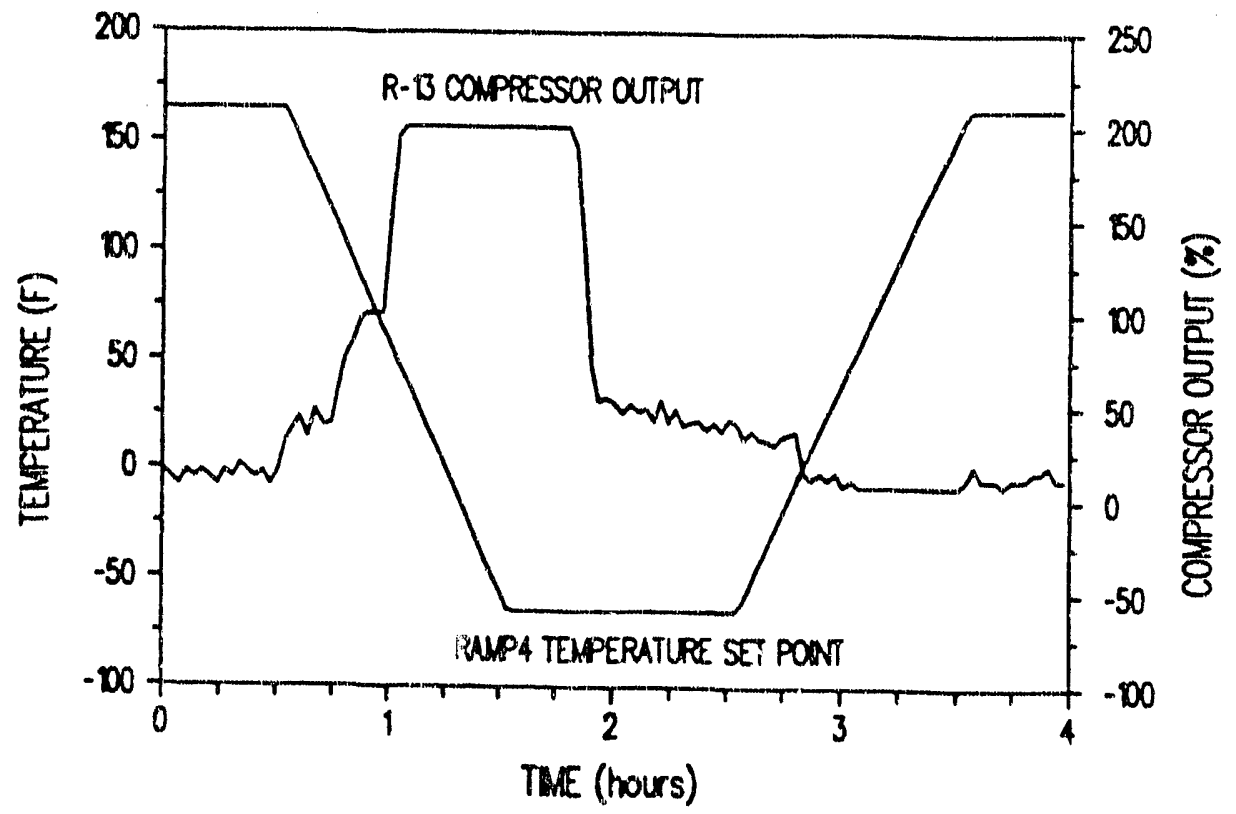

Figure 6.4 EC-196 Temperature and R-13 Compressor output Response. 


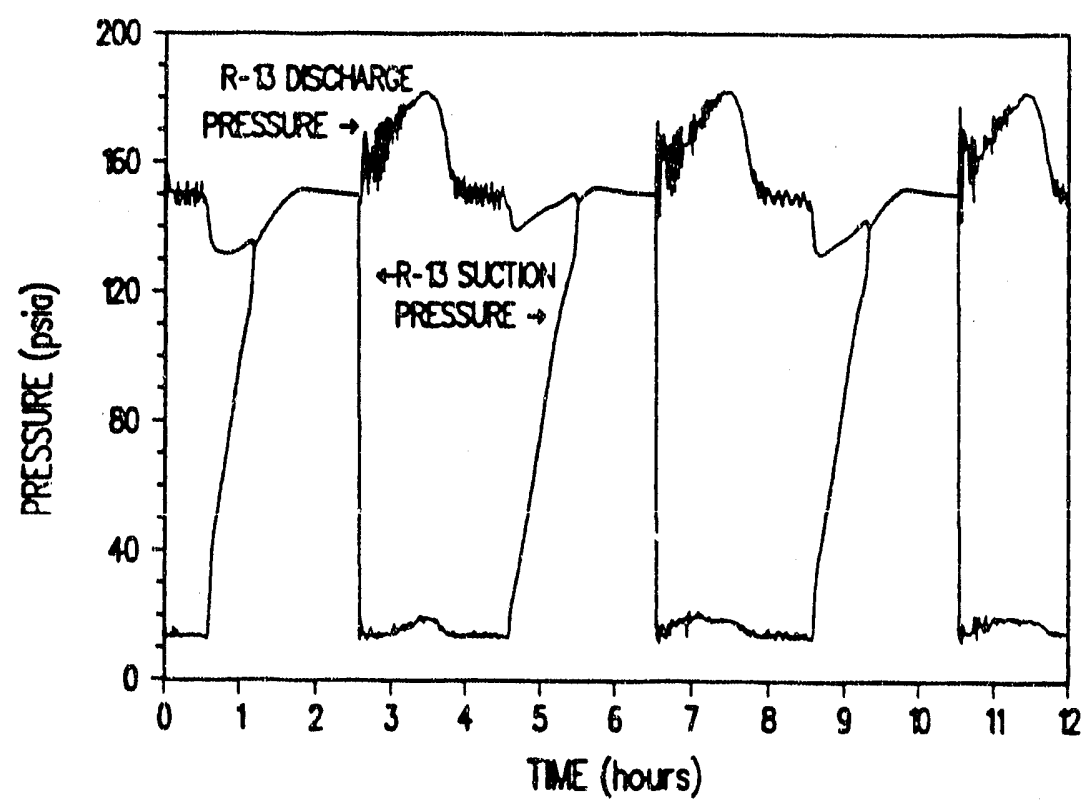

Figure 6.5 Conventional (Stand-Alone Chamber) R-13 Suction and Discharge Pressure Response.

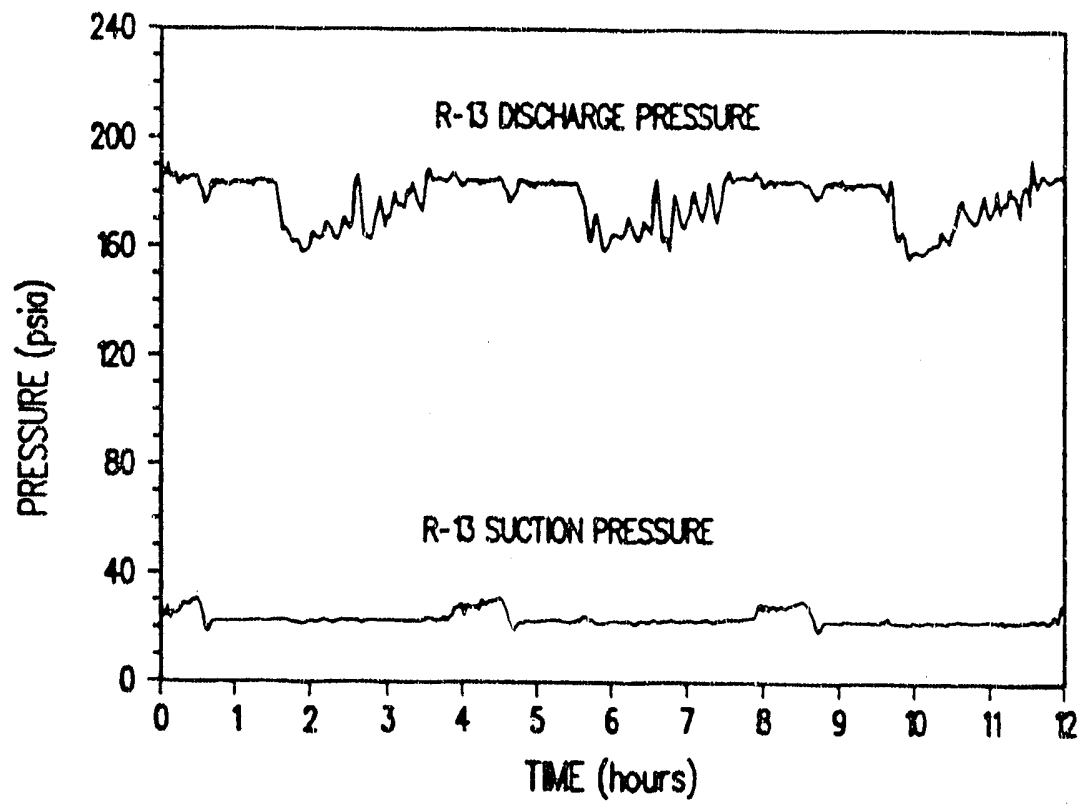

Figure 6.6 CCRS R-13 Suction and Discharge Pressure Response. 


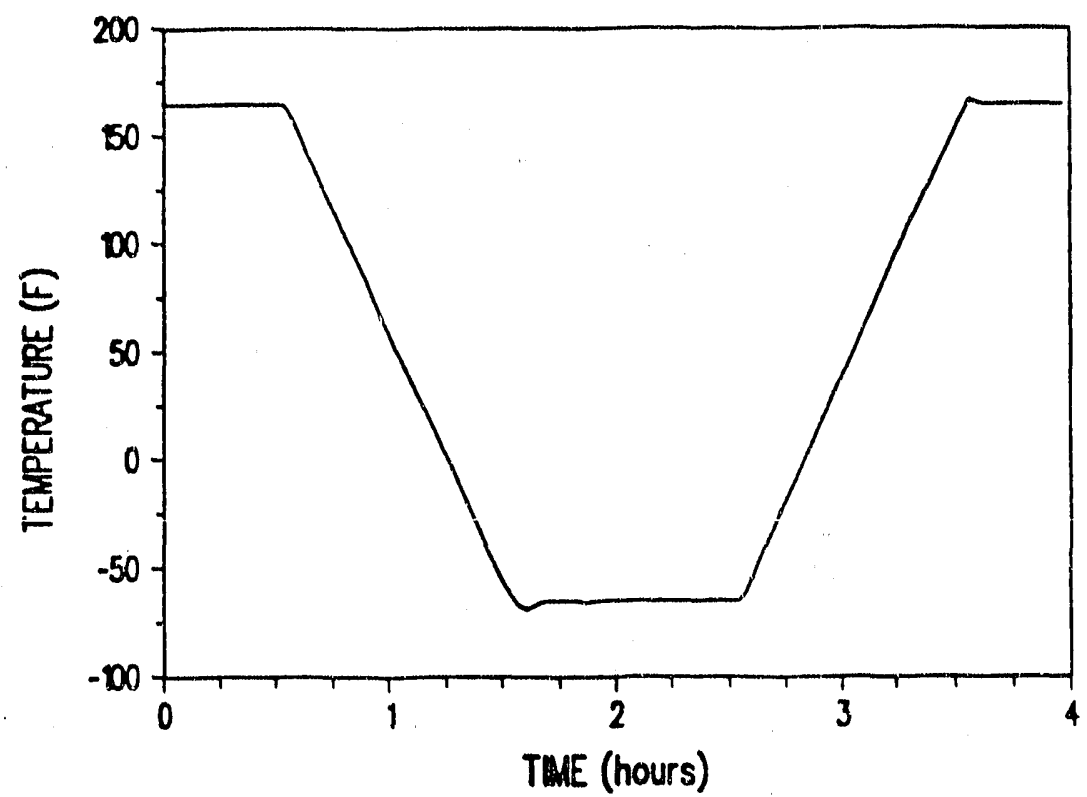

Figure 6.7 Chamber Temperature Response to RAMP4 Profile.

\subsection{Chamber Performance}

A typical temperature response of a chamber on the CCRS simulating the RAMP4 cycle is shown in Figure 6.7. The temperature undershoot is less than $4^{\circ} \mathrm{F}$, and the setpoint is controlled within $\pm 1.0^{\circ} \mathrm{F}$.

The performance of a refrigeration system is usually specified by the maximum linear ramp or pull-down rate of the temperature chamber. The maximum pull-down rate was determined under two operating scenarios. First, all the chambers on the system were started simultaneously to determine the response to the peak loading condition. In the second scenario, all the chambers were started 15 to 30 minutes apart to determine the pull-down rate to a more realistic load where only one pair of compressors was operational. The performance of REFCON was evaluated using the peak load condition. The conventional chamber used for comparison purposes has a test volume of 27 ft. 3 , and a rated pull-down of at least $4^{\circ} \mathrm{F} / \mathrm{min}$. with $7.5 \mathrm{HP}$ compressor motors. 


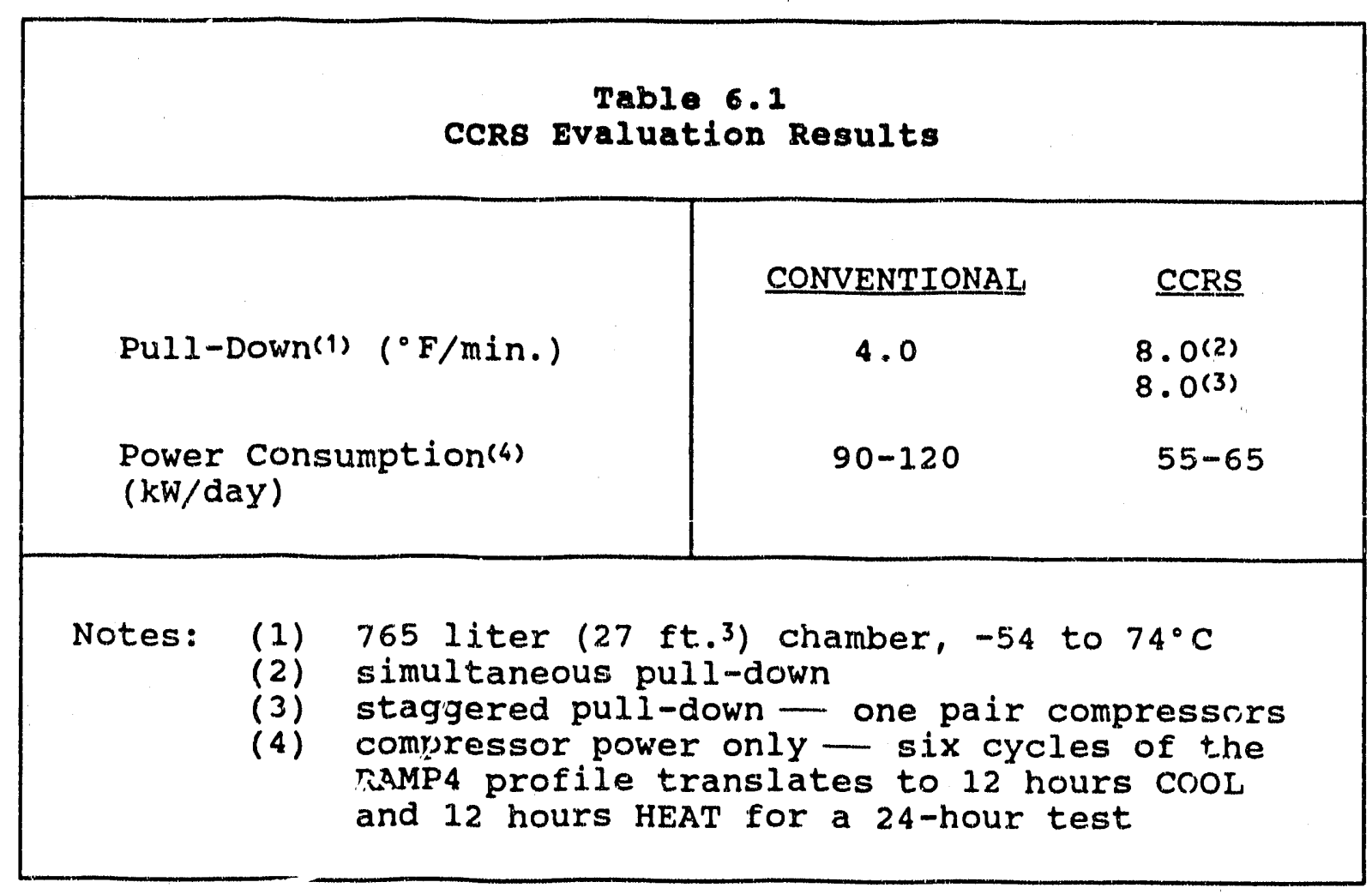

The pull-down performance of a $27 \mathrm{ft} .3$ chamber on the CCRS is compared to a conventional stand-alone chamber in Table 6.1. The CCRS had twice the pull-down rate of the conventional chamber during simultaneous pull-down (which required the extra compressor capacity from the redundant compressors). However, if only one pair of compressors is used, the pull-down rate is only $5^{\circ} \mathrm{F} / \mathrm{min}$. If the chambers are staggered (i.e., each chamber is started 15 to 30 minutes apart), the CCRS can still maintain a pull-down rate of $8^{\circ} \mathrm{F} / \mathrm{min}$. There is a design tradeoff between pull-down rate and temperature control in the chamber. Refrigeration systems designed for maximum pull-down sacrifice temperature control. For the CCRS and conventional chamber, the pull-down rate was limited to allow for no more than $5^{\circ} \mathrm{F}$ overshoot. Temperature overshoot of $5^{\circ} \mathrm{F}$ is defined as exceeding the low temperature setpoint, such as $-70^{\circ} \mathrm{F}$, when the desired setpoint is $-65^{\circ} \mathrm{F}$. The CCRS allows each chamber on the network to have the compressor output for fast pull-down rates when it is needed. 


\subsection{System Efficiency}

System efficiency is not to be confused with the coefficient of performance, COP, which compares different types of

refrigeration system designs. The CCRS, and most conventional chambers, employ the same refrigeration systern design

(discussed in section 3.1). The system efficiency for the CCRS should increase if false loading of the compressors is

eliminated. The savings is offset by the additional power consumption required to keep the CCRS operating on a continual basis.

Figure 6.8 compares the compressor output under the simultaneous pull-down and staggered starts. The staggered start represents a realistic mode of operation where all the test chambers have been started in 30-minute intervals. The minimum compressor output for the staggered start is approximately $50 \%$ as compared to $7.6 \%$ (lowest possible value) for the simultaneous pull-down case. A larger percentage of the available compressor capacity is being utilized, which reduces the need for any false loading by either the compressors or the economizers.

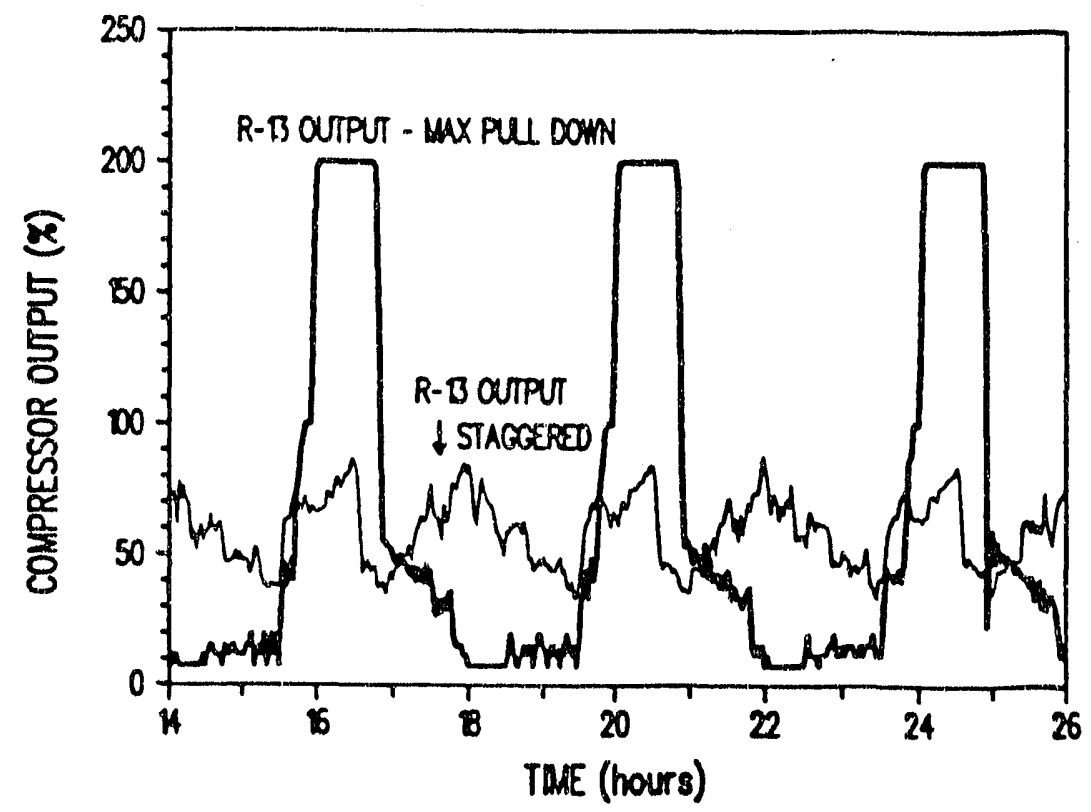

Figure 6.8 R-13 Compressor output for staggered and Maximum Pull-Down Rates Using the RAMP4 Profile. 
In order to quantify the increase in overall system efficiency, the input supply power to the compressor motors on both the CCRS and a conventional chamber (previously described in the Chamber Performance section) was measured during the simulation on the RAMP4 profile. The power consumed by the chamber heaters and fans, etc., was excluded.

All the chambers on the CCRS were started at the same time (simultaneous pull-down). The minimum CCRS power was measured when all the chambers were simulating the $165^{\circ} \mathrm{F}$ environment. The minimum power is dependent on the compressor false load provided by each of the long line economizers. By prorating the minimum power to each chamber according to its test volume, it was determined that a $27 \mathrm{ft.} 3$ chamber on the cCRs uses about $1 / 7$ of the total power measured on the CCRS compressors. To obtain a reasonable estimate of power consumption, both systems were evaluated over a 24-hour period since conventional chambers normally disable the refrigeration system during the $165^{\circ} \mathrm{F}$ environment while the CCRS operates at minimum power.

The efficiency of the CCRS is compared to the conventional chamber for both the peak and staggered load conditions in Table 6.1. The CCRS uses approximately 55\% less power than a conventional chamber. The decrease in power consumption is attributed primarily to the reduction in compressor false loading. While the power consumption varies between different chamber models, the CCRS consumes less power than any conventional chamber during steady-state cooling because the compressor output is controlled. 


\subsection{CONCLUSIONS}

The approach of using a centralized refrigeration system has always been viewed with uncertainty. The CCRS has demonstrated that the concept of using a centralized refrigeration system to support several temperature chambers outperforms conventional chambers. Additionally, the CCRS is more efficient (consumes less energy) than typical stand-alone chambers. Other benefits of the CCRS include the stacking of similar sized chambers to reduce floor space requirements, ease of maintenance with one system that uses identical compressors, and acoustically isolating the refrigeration system. Ideally, the CCRS should be located in a basement beneath the test bay, which would isolate the compressor noise and eliminate any need for pitching suction lines for oil return from chamber evaporators. It is hoped that equipment manufacturers can refine the CCRS concept so that customers who desire to replace several chambers with a centralized network will have an economical alternative.

\subsection{RECOMMENDATIONS}

The CCRS control system should be optimized for cost and simplicity. The A/C drive purchased has much more capability than is actually needed. If a lower-priced $A / C$ drive, which satisfies the requirements of the CCRS can be located, the control system could be simplified by utilizing $A / C$ drives on the $R-502$ system. In this scenario, compressor cylinder unloading could be eliminated. With advances in programmable Logic Controllers (PLCs), it seems quite probable that the REFCON PC can be replaced with a simpler and more costefficient controller.

The total part cost of the CCRS exceeded the replacement cost of conventional chambers by 10\%. The acquisition cost of the test chambers equipped only with evaporators was much higher than had been anticipated. Theses units were as expensive as standard models even though the refrigeration compressor and associated labor costs were excluded. In indepth survey of manufacturers needs to be conducted to determine if a larger chamber order (greater than five) would drive the unit price to a reasonable level. 
1. M. D. Burghardt, Engineering Thermodynamics with Applications. Harper and Row, 1978, pp 227-240.

2. ASHRAE (American Society of Heating, Refrigerating, and Air-Conditioning Engineers, Inc.), 1986 Handbook: Refrigeration systems and Applications. ASHRAE. Atlanta, $\mathrm{GA}, 1986$

3. Althouse, A. D., Turnquist, C. H. and Bracciano, A. F., Modern Refrigeration and Air-Conditioning, Fourth Edition. Goodheart-Wilcox Co., Inc. South Holland, IL, 1982)

4. Robert G. Baca, Proceedings of the Institute of Environmental Sciences: Development of a Vapor Compression Refrigeration System for a Network of Nine Chambers. Sandia National Laboratories. Albuquerque, NM, 1989.

5. K. M. Miller, 7543, Internal Memorandum to Distribution, subject: Chamber control on the climatic central Refrigeration system. November 1, 1989.

6. K. M. Miller and R. G. Baca, 7543, Internal Memorandum to Distribution, subject: Climatic Centralized Refrigeration System Control Software Revision. March 29, 1989.

7. Invisible Software, Inc., Invisible Network NET/30 Network operating system Software Manual. Invisible Software Inc., Foster City, CA. 


\section{APPENDIX A}

\section{Compressor station schematic}

A drawing of the mechanical system for the CCRS Central. Compressor station is presented as Figure $\mathrm{A}-1$; a list of major components is given in Table $A-1$. In general, the drawing contents and the table contents will be familiar to personnel employed in the design and maintenance of refrigeration equipment. 


\begin{tabular}{|c|c|c|}
\hline \multicolumn{3}{|c|}{$\begin{array}{c}\text { TABLE A-1 } \\
\text { Component List }\end{array}$} \\
\hline Component Item & Manufacturer & Model \\
\hline Cascade Condenser & Russielis & Custom-Built \\
\hline $\begin{aligned} \text { Cascade } \mathrm{TE} & \text { - Valve } \\
& \text { - solenold }\end{aligned}$ & $\begin{array}{l}\text { Sporlan } \\
\text { Sporlan }\end{array}$ & $\begin{array}{l}\text { GRE } 1-1 / 2 \quad \mathrm{C} \\
\mathrm{A} 3 \mathrm{~S}_{1}\end{array}$ \\
\hline Compressor R-13 & Carrier & $5 F 60$ \\
\hline Compressor R-502 & Carrier. & $5 F 60$ \\
\hline Desuperheater & CSI & Custom-Built \\
\hline Discharge Check & Henry & 205 \\
\hline Dump Valves & $\mathrm{A}-\mathrm{P}$ & $239 \mathrm{BC}-140-290$ \\
\hline Filter-Drier & Sporlan & C969-G \\
\hline $\begin{aligned} \text { Hot Gas Bypass - Valve } \\
\text { - Solenoid }\end{aligned}$ & $\begin{array}{l}\text { Sporlan } \\
\text { Sporlan }\end{array}$ & $\begin{array}{l}\text { ADRPE }-3-0-30 \\
\text { MB10S2 }\end{array}$ \\
\hline Liquid Sight Glass & Sporlan & $S A-175$ \\
\hline Oil Cooler (Water-Cooled) & Temprite & $5 F 20 B 103$ \\
\hline Oil Level Regulator & $\mathrm{AC} \& \mathrm{R}$ & $s-9120-C$ \\
\hline Oil Res. Vent Check & AC\&R & $s-9103$ \\
\hline Oil Reservoir & AC\&R & $s-9109$ \\
\hline Oil Separator & Henry & 507 \\
\hline Pressure Relief/Bypass & Henry & 925 \\
\hline Refrig. Receiver TE Valve & Sporlan & GR 1 Z \\
\hline Refrigerated Receiver & Standard & H8542 \\
\hline $\begin{aligned} & \text { suction Cool TE - Valve } \text { - Solenoid } \\
&\end{aligned}$ & $\begin{array}{l}\text { Sporlan } \\
\text { Sporlan }\end{array}$ & $\begin{array}{l}\mathrm{GFE} 1 / 2 \mathrm{C} \\
\mathrm{B} 6 \mathrm{~S}_{1}\end{array}$ \\
\hline Surge Tank/Receiver & standard & 7201 \\
\hline Water Control Valve (Cond.) & Penn & V46AR $1-1 / 2$ \\
\hline Water-Cooled Condenser & Carrier & $09 \mathrm{RH} 027$ \\
\hline
\end{tabular}




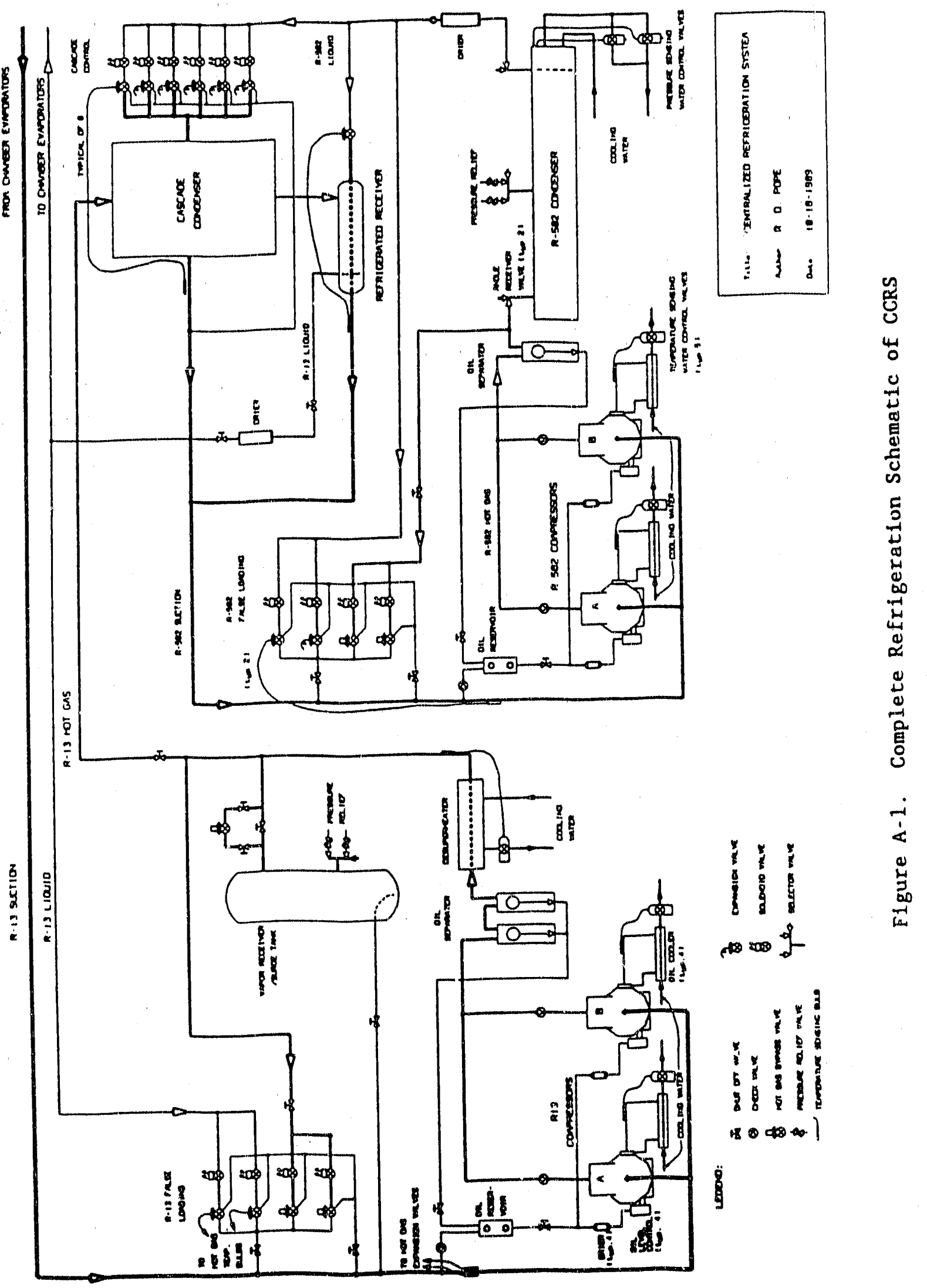



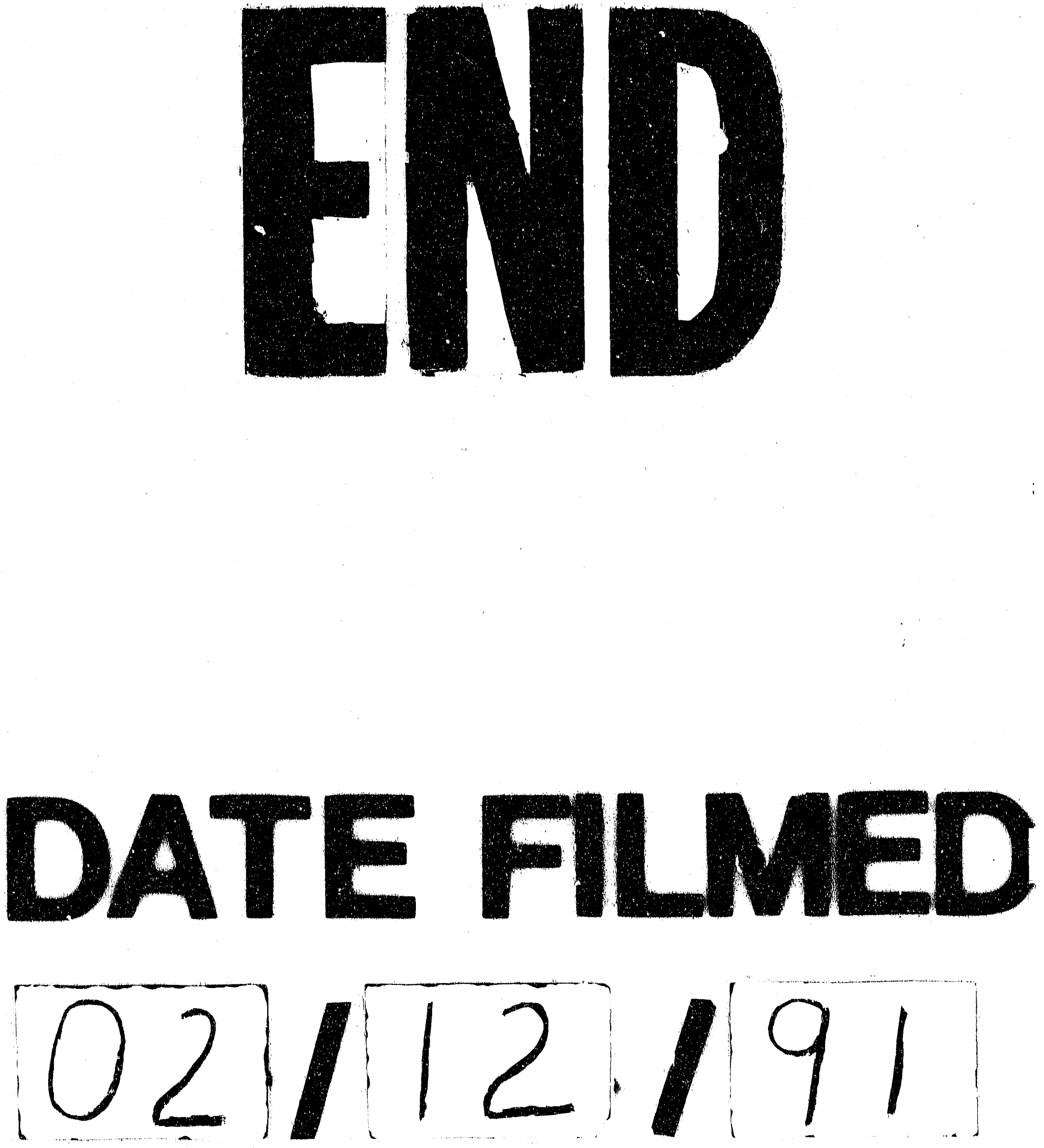
